\title{
Contributions of Family Leisure to Family Functioning Among Families That Include Children With Developmental Disabilities
}

Dorthy Clara Hornberger Dodd

Brigham Young University - Provo

Follow this and additional works at: https://scholarsarchive.byu.edu/etd

Part of the Recreation Business Commons

\section{BYU ScholarsArchive Citation}

Dodd, Dorthy Clara Hornberger, "Contributions of Family Leisure to Family Functioning Among Families That Include Children With Developmental Disabilities" (2007). Theses and Dissertations. 862.

https://scholarsarchive.byu.edu/etd/862

This Thesis is brought to you for free and open access by BYU ScholarsArchive. It has been accepted for inclusion in Theses and Dissertations by an authorized administrator of BYU ScholarsArchive. For more information, please contact scholarsarchive@byu.edu, ellen_amatangelo@byu.edu. 
CONTRIBUTIONS OF FAMILY LEISURE TO FAMILY FUNCTIONING

AMONG FAMILIES THAT INCLUDE CHILDREN WITH

DEVELOPMENTAL DISABILITES

\author{
by \\ Dorthy C. H. Dodd \\ A thesis submitted to the faculty of \\ Brigham Young University \\ in partial fulfillment of the requirements for the degree of \\ Master of Science
}

Department of Recreation Management and Youth Leadership

Brigham Young University

August 2007 
BRIGHAM YOUNG UNIVERSITY

GRADUATE COMMITTEE APPROVAL

of a thesis submitted by

Dorthy C. H. Dodd

This thesis has been read by each member of the following graduate committee and by majority vote has been found to be satisfactory.

Date

Date

Date
Ramon B. Zabriskie, Chair

Mark A. Widmer

Dennis L. Eggett 


\section{BRIGHAM YOUNG UNIVERSITY}

As chair of the candidate's graduate committee, I have read the thesis of Dorthy C. H. Dodd in its final form and have found that (1) its format, citations, and bibliographical style are consistent and acceptable and fulfill university and department style requirements; (2) its illustrative materials including figures, tables, and charts are in place; and (3) the final manuscript is satisfactory to the graduate committee and is ready for submission to the university library.

Date

Accepted for the Department
Ramon B. Zabriskie

Chair, Graduate Committee
Pattie Ann Freeman

Chair, Department of Recreation Management and Youth Leadership

Accepted for the College

Gordon B. Lindsay, Associate Dean

College of Health and Human Performance 


\begin{abstract}
CONTRIBUTIONS OF FAMILY LEISURE TO FAMILY FUNCTIONING

AMONG FAMILIES THAT INCLUDE CHILDREN WITH

DEVELOPMENTAL DISABILITES
\end{abstract}

\author{
Dorthy C. H. Dodd \\ Department of Recreation Management and Youth Leadership \\ Master of Science
}

The purpose of this study was to examine the relationship between family leisure involvement and family functioning among families that include children with developmental disabilities. The sample consisted of 154 families (154 parents and 62 youth). Data were analyzed from the parent, youth, and family perspective. The Family Leisure Activity Profile (FLAP) was used to measure family leisure involvement. FACES II was used to measure family functioning. A scale based upon the definition, classification, and systems of support manual of the American Association on Mental Retardation adapted by Dyches was used to measure the level of support needed by the child with a developmental disability. Blocked multiple regression analysis indicated a positive relationship between core family leisure and family cohesion, adaptability and overall family functioning, but the analyses indicated no relationship between balance family leisure and family cohesion, adaptability, and overall family functioning from all 
three perspectives. Results also indicated that family functioning and family leisure involvement were very similar between traditional families and families including children with developmental disabilities. Implications for practitioners and recommendations for further research are discussed. 


\section{ACKNOWLEDGMENTS}

I would like to thank the many people who helped me complete this project. First I would like to thank Ramon Zabriskie for his patience, time, and support in working with me, Mark Widmer for his time and editing, and Dennis Eggett for his time and help in the analysis. I would like to give special thanks to The Arc of United States, Texas Counsel for Developmental Disabilities, and the National Down Syndrome Society for their help in finding participants.

I would like to thank my family for their support, especially my husband, Paul Dodd, for his encouragement in helping me accomplish my goal and his genuine support throughout the process, and my children Jacob, Westley, and Isaac for their patience. I would also like to express my appreciation for my sisters, Kathaleen Dodd for editing and child care as well as Hermie Morgan, and Karen Hornberger for their child care. I want to give special thanks to my sister Laurel Hornberger for joining me in this adventure, and for her support and encouragement throughout the whole process. I would never have completed this without you. It was you that made this really possible. Thank you!

Finally, I would like to express my gratitude for my Heavenly Father and Savior Jesus Christ for the strength and guidance they give me and for the people that have been placed in my life. This project was only possible because of the many people who supported and encouraged me. Thank you. 


\section{Table of Contents}

List of Tables viii

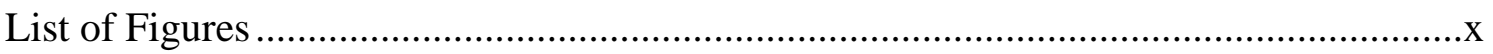

Contributions of Family Leisure to Family Functioning Among Families that Include Children with Developmental Disabilities

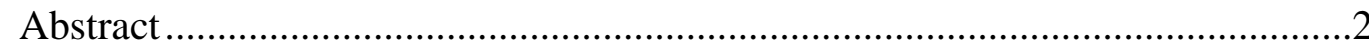

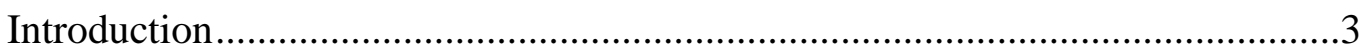

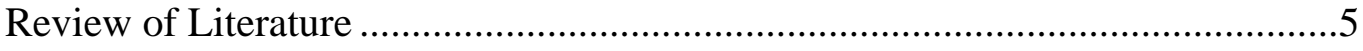

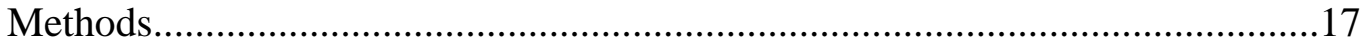

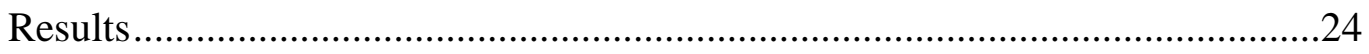

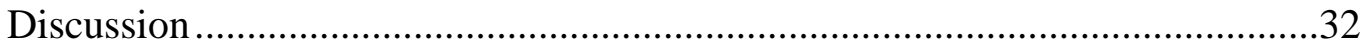

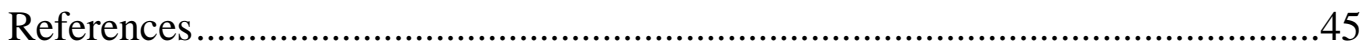

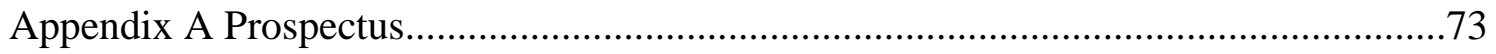

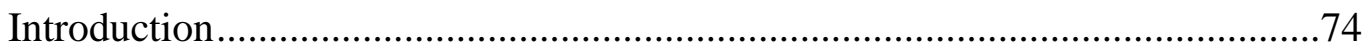

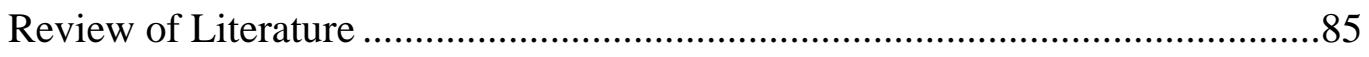

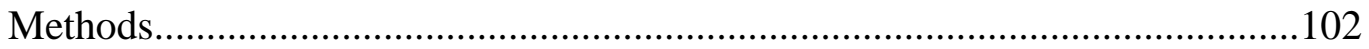

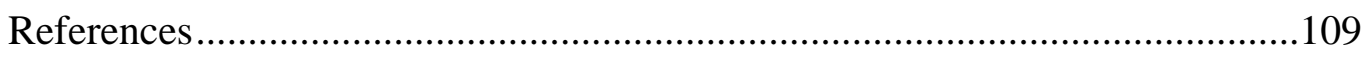

Appendix A-1a Informed Consent..............................................................117

Appendix A-1b Family Leisure Activity Profile ...........................................120

Appendix A-1c Family Adaptability and Cohesion Scale II ............................134

Appendix A-1d Dyches Adapted Support/Skills Scale ..................................136

Appendix A-1e Demographic Questions ...................................................138 


\section{List of Tables}

Table

Page

1 Differences Between Families with a Child with a Developmental

Disability and Normative Families on Cohesion, Adaptability, and

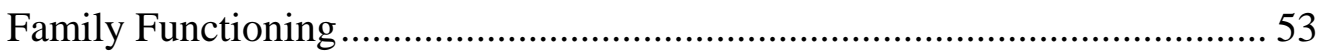

2 Differences Between Families with a Child with a Developmental

Disability and Normative Families on Family Leisure Patterns .................... 54

3 Zero Order Pearson Correlations: Parent Data ............................................. 56

4 Zero Order Pearson Correlations: Youth Data................................................ 58

5 Zero Order Pearson Correlations: Family Data (Parent \& Youth) ................. 60

6 Summary of Blocked Regression Equations Predicting Family

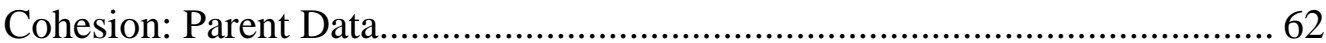

7 Summary of Blocked Regression Equations Predicting Family

Adaptability: Parent Data

8 Summary of Blocked Regression Equations Predicting Family

Functioning: Parent Data 64

9 Summary of Blocked Regression Equations Predicting Family

Cohesion: Youth Data. 65

10 Summary of Blocked Regression Equations Predicting Family

Adaptability: Youth Data..... 66

11 Summary of Blocked Regression Equations Predicting Family

Functioning: Youth Data. 
12 Summary of Blocked Regression Equations Predicting Family

Cohesion: Family Data (Parent \& Youth) ……………………………............ 68

13 Summary of Blocked Regression Equations Predicting Family

Adaptability: Family Data (Parent \& Youth).................................................... 69

14 Summary of Blocked Regression Equations Predicting Family

Functioning: Family Data (Parent \& Youth) ………………………................ 70 


\section{List of Figures}

Figure Page

1 Olsen’s Family Circumplex Model.........................................................71

2 Core and Balance Model of Family Leisure Functioning..............................72 
Running head: FAMILY LEISURE AND FUNCTIONING

Contributions of Family Leisure to Family Functioning Among Families that Include Children with Developmental Disabilities

Dorthy C. H. Dodd, M.S.

Brigham Young University

Ramon B. Zabriskie, Ph.D.

Brigham Young University 


\title{
2 Family Leisure and Functioning
}

\author{
Abstract \\ The purpose of this study was to examine the relationship between family leisure \\ involvement and family functioning among families that include children with \\ developmental disabilities. The sample consisted of 154 families (154 parents and 62 \\ youth). Data were analyzed from the parent, youth, and family perspective. The Family \\ Leisure Activity Profile (FLAP) was used to measure family leisure involvement. FACES \\ II was used to measure family functioning. A scale based upon the definition, \\ classification, and systems of support manual of the American Association on Mental \\ Retardation adapted by Dyches was used to measure the level of support needed by the \\ child with a developmental disability. Blocked multiple regression analysis indicated a \\ positive relationship between core family leisure and family cohesion, adaptability and \\ overall family functioning, but the analyses indicated no relationship between balance \\ family leisure and family cohesion, adaptability, and overall family functioning from all \\ three perspectives. Results also indicated that family functioning and family leisure \\ involvement were very similar between traditional families and families including \\ children with developmental disabilities. Implications for practitioners and \\ recommendations for further research are discussed.
}

Key words: adaptability, cohesion, core and balance family leisure, developmental disability, family functioning, family leisure. 
Family Leisure and Functioning 3

Contributions of Family Leisure to Family Functioning Among Families that Include Children with Developmental Disabilities

Introduction

Researchers consistently find positive relationships between family leisure involvement and family functioning (Freeman \& Zabriskie, 2003; Orthner \& Mancini, 1991; Zabriskie, 2000, 2001; Zabriskie \& Freeman, 2004; Zabriskie \& McCormick, 2001, 2003). Although many studies examine leisure among traditional families, very little research focuses on nontraditional families. Scholars (Mactavish \& Schleien, 1997, 1998, 2004) have called for a greater understanding of family leisure among families who have children with developmental disabilities.

Families that include a child with a developmental disability face a unique set of challenges and stressors (Singer, 2002). Many researchers (Glidden, 1993; Mactavish \& Schleien, 1997; Olsson \& Hwang, 2001; Summers et al., 2005; Warfield, Krauss, HauserCram, Upshur, \& Shonkoff, 1999) agree that families who have children with developmental disabilities face substantially greater challenges and have higher levels of stress than families without children with disabilities. Contrary to previous research (Kronick, 1976; Margalit \& Heiman, 1986), current researchers (Cahill and Glidden, 1996; Dyson, 1996; Ferguson, 2002) have found that although families of children with developmental disabilities face greater challenges and stress, they still function at or near the same levels as traditional families without children with disabilities. They have positive and cohesive family relationships (Dyson, 1996). 


\section{Family Leisure and Functioning}

Olson (2000) suggests that a family’s ability to successfully function as a system is demonstrated through its capacity to meet their needs for cohesion and adaptability. Zabriskie and Freeman (2004) argue that such needs are often met through family leisure involvement. Recent studies among various family types (Freeman \& Zabriskie, 2003; Zabriskie \& Freeman, 2004; Zabriskie \& McCormick, 2001, 2003) have followed Orthner and Mancini’s (1991) recommendation of using a family systems perspective as a theoretical framework from which to examine the contributions of family leisure. These studies have consistently supported the relationship between family leisure involvement and family functioning among a variety of family structures such as families with adoptive children of color (Freeman and Zabriskie, 2003; Zabriskie \& Freeman, 2004), Hispanic families (Christenson, Zabriskie, Eggett, \& Freeman, 2006), and single parent families (Smith, Taylor, Hill, \& Zabriskie, 2004). Researchers (Freeman \& Zabriskie, 2003; Zabriskie, 2000, 2001; Zabriskie \& Freeman, 2004; Zabriskie \& McCormick, 2001, 2003) have called for further known group studies including families of children with developmental disabilities.

Research examining leisure in these families is in its infancy (Mactavish \& Schleien, 1997, 2004; Mactavish, Schleien, \& Tabourne, 1997; Scholl, McAvoy, Rynders, \& Smith, 2003). While the studies completed up to this point provide a sound basis for this emerging line of research, they have primarily used qualitative methodologies with relatively small samples sizes. The next logical step in this line of research is to examine the contributions of family leisure involvement to measurable outcomes (such as aspects of family functioning) in larger samples of families who have 
Family Leisure and Functioning 5

a child with a disability. This will not only further this line of study, but also provide insight and direction for researchers and practitioners attempting to strengthen families and improve family functioning in families that include children with developmental disabilities.

Review of Literature

Families of Children with Developmental Disabilities

Historically children with disabilities did not reside with their families, but instead were institutionalized (Landesman \& Vietze, 1987). Therefore, they had little contact with their families. This began to change in the 1960s as the idea of normalization emerged. Normalization was an attempt to increase the rights of individuals with disabilities to give them culturally normal life conditions. As a result, children with disabilities began to live with their families or in family situations rather than institutions (Landesman \& Vietze, 1987). Since that time, children with developmental disabilities have lived in diverse family situations. While most of these children live in nuclear families with their biological parents and siblings (Mactavish et al., 1997), still, many of these children live in single parent homes, adoptive homes, foster homes that do not culminate into permanent adoptive homes (Landesman \& Vietze, 1987), or group homes. "Family” for these children has come to mean, “a social group with whom one resides” (Landesman \& Vietze, 1987, p. 61). For at least four decades, a popular focus of research in the disability studies has been families that include children with developmental disabilities (Singer, 2002). 


\section{Family Leisure and Functioning}

Early researchers tended to "make blanket attributions characterizing (such) families as maladaptive and marked by pathology” (Singer, 2002, p. 150). This was due in large part to a lack of comparison groups, samples that only represented families seeking services, use of instruments without rigorous psychometric development, lack of replication, and results from mothers generalized to the entire family (Glidden, 1993). Uncritical acceptance of this view is dangerous because "adjustment or maladjustment is dependent not only on the presence or absence of stress, but also on the presence or absence of positive outcomes. Positive outcomes can coexist and even be orthogonal to negative outcomes” (Glidden, 1993, p. 482). Because researchers were not looking for and hypothesizing positive outcomes associated with having a child with a disability in a family, they were not finding any (Glidden, 1993). Researchers (Blacher, 2001; Ferguson, 2002; Kwai-sang \& Li-Tsang, 1999; Singer, 2002; Taunt \& Hastings, 2002) are beginning to examine and identify benefits of having a child with a disability in a family. It is only recently that studies show these families can cope effectively and adjust positively to the added demands of raising a child with a disability (Blacher, 2001; Ferguson, 2002; Taunt \& Hastings, 2002).

Although benefits may be associated with raising a child who has a developmental disability, heavy demands and increased challenges are also likely (Glidden, 1993; Mactavish \& Schleien, 1997; Olsson \& Hwang, 2001; Summers et al., 2005; Warfield et al., 1999). These children often have challenging behaviors, and require high levels of supervision as well as extensive long-term medical care. They also may place high physical and emotional demands on their parents (Singer, 2002). Each 
family is unique in its level of resiliency and ability to adapt to the added demands and stress associated with caring for a child with a disability. The presence of stress and demands does not necessarily cause maladjustment and low functioning in a family; in fact, families that adjust and cope well experience high levels of family functioning. Family Functioning in Families of Children with Developmental Disabilities.

Stability and change are two opposing needs that influence individual behavior, (Iso-Ahola, 1984) and family systems (Klein \& White, 1996). A family system must meet the "need for stability in interactions, structure, and relationships, as well as a need for novelty in experience, input, and challenge” (Zabriskie \& McCormick, 2001, p. 283) in order to function effectively. According to the Circumplex Model (Olson, 1986) two main constructs (cohesion and adaptability) influence the level of family functioning. Family cohesion refers to feelings of personal relatedness and family closeness, while family adaptability refers to a family’s ability to develop, adapt, and function as a working unit. Klein and White (1996) describe families as "goal directed, self-correcting, dynamic, interconnected systems that both affect and are affected by their environment and by qualities within the family system itself” (p. 281).

For 70-80 years prior to this decade, professionals assumed that children with disabilities inevitably damaged their families and created a high degree of pathology in their family functioning (Ferguson, 2002). A family of a child with a developmental disability was even considered to be a disabled family (Glidden, 1993). Because these families report increased pressure and demands along with added stress and challenges (Dyson, 1996; Fuller \& Rankin, 1994; Mactavish et al., 1997), researchers assumed they 


\section{Family Leisure and Functioning}

were lower functioning. Until recently, researchers reported mixed results describing family functioning in these families (Summers et al., 2005). Some studies reported these families as malfunctioning (Kronick, 1976) and deviating from the normal range of family cohesion and adaptability (Michaels \& Lewandowski, 1990) while others reported them as having adaptational profiles resembling, in range and number, those profiles of families with children without disabilities (Baxter, Cummins, \& Polak, 1995; Krauss \& Seltzer, 1993). The most recent research agrees that most families of children with disabilities adjust positively and cope effectively with the added demands of raising a child with a developmental disability (Blacher, 2001; Ferguson, 2002; Taunt \& Hastings, 2002). In fact, family functioning in families with children with disabilities is similar to traditional families with children who achieve at normal levels (Dyson, 1996).

Families with children with learning disabilities have positive and cohesive family relationships and use rules for operating the family routine. Increased parental stress, emphasis placed on personal growth, and altered routines, are disadvantages for these families but they do not cause family dysfunction. Cahill and Glidden (1996) found these families with children who have disabilities function at or near normal levels based on families in general. In fact, according to Ferguson (2002), an increasingly dominant body of research has found patterns of overall adjustment and well-being to be similar in groups of families with and without children with disabilities (Blacher, 2001; Ferguson, 2002; Taunt \& Hastings, 2002). Many parents are able to adapt care to the special demands of their children with disabilities, resulting in parental adaptation rather than parental dysfunction (Roach, Orsmond, \& Barratt, 1999). Understanding the behaviors 
that lead families with children who have disabilities to function at high levels may provide valuable insight that could help other families and parents.

Family leisure involvement is consistently related to family functioning and quality of family life among traditional families (Hawks, 1991; Holman \& Epperson, 1989; Orthner \& Mancini, 1991; Zabriskie \& McCormick, 2001). Scholars also report that family leisure contributes to family functioning among families with different structures such as those with transracial adoptive children (Freeman \& Zabriskie, 2003; Zabriskie \& Freeman, 2004), single-parent families (Smith et al., 2004), and Hispanic families living in the United States (Christenson et al., 2006). Studies among families with children who have developmental disabilities have reported similar findings (Mactavish \& Schleien, 1998; Mactavish \& Schleien, 2004; Scholl et al., 2003). Joint leisure is perceived as a mode of promoting overall quality of life, and helping family members learn life skills (Mactavish \& Schleien, 1998). In families with high levels of stress (i.e., families with children with developmental disabilities), this correlation between family functioning and family leisure may be vital for helping families function at a healthy level.

\section{Family Leisure in Families of Children with Developmental Disabilities}

Much of the research on families of children with developmental disabilities has focused on identifying and describing their leisure patterns. Differences exist between their recreation patterns and those of a traditional family (Mactavish et al., 1997), but further understanding of family leisure in families that include children with developmental disabilities is needed (Mactavish \& Schleien, 2004). Families of children 


\section{Family Leisure and Functioning}

with disabilities usually engage in leisure involving two or more, but not all family members. Previous research concluded that most family leisure occurs within the home (United Media, 1982), but according to Mactavish and Schleien (1997) family leisure in families of children with developmental disabilities occurs as frequently in a community setting as in the home.

Research (Scholl et al., 2003) shows that outdoor recreation experiences are beneficial to families of children with developmental disabilities because they increase knowledge and confidence in recreation participation as a family, and improve relationships both inside and outside the family. Parents of children with disabilities face challenges similar to a typical family such as limited money, balancing the needs of all family members, supervision of children, lack of energy, and knowledge, and/or skills; however, for parents of children with developmental disabilities, medical, economic, care-giving demands are greater, and the facilitation of appropriate social interactions are both physically and emotionally draining. The constraints on these families limit their leisure options (Scholl et al.).

Parents of children with disabilities view family leisure as "highly important and beneficial for enhancing quality of family life and promoting development of life-long leisure skills and interests” (Mactavish \& Schleien, 2004, p. 137). Siblings without disabilities seem to adopt individual leisure patterns by their adolescence, but children with disabilities rely heavily on family recreation into early adulthood or longer (Horna, 1994). Although family leisure is very important for the whole family, parents feel it is particularly important for their children with disabilities because it is not only "a vehicle 
for skill and self development, but offer(s) the most accepting and potentially enduring leisure and social outlet for their children with a disability” (Mactavish \& Schleien, 2004, p. 137). As a result, much of the leisure in families with children who have disabilities has a strong child-centered focus (Mactavish \& Schleien, 1997; Mactavish et al., 1997). Family leisure is not a stress-coping strategy for these families because it often increases the stress, but the benefits of family leisure seem to surpass the negative aspects of increased stress. Family leisure is greatly valued by both parents and children with disabilities (Horna, 1994; Mactavish \& Schleien, 2004).

\section{Family Leisure}

Leisure professionals suggest that today leisure is the single most important force developing cohesive, healthy relationships between husband and wives and between parents and their children (Couchman, 1988). Family leisure studies were first performed in the 1930s (Hawks, 1991), and since that time they have improved in both their theoretical framework and their statistical analysis. Current studies and new theoretical models in family research "provide greater understanding and vital direction for the development and provision of services that are likely to strengthen families” (Zabriskie, 2001, p. 30). In 1998, Orthner (1998) criticized parks and recreation professionals for not committing sufficient time and resources to family leisure and its value for family togetherness. He then went on to challenge them to focus on and strengthen the most vital institution in society, the family. Since this challenge, interest in family leisure has increased significantly (Zabriskie, 2001). 


\section{Family Leisure and Functioning}

Research has consistently found positive relationships between family leisure involvement and positive family functioning (Hawks, 1991; Holman \& Epperson, 1989; Orthner \& Mancini, 1991; Zabriskie \& McCormick, 2001). Family leisure plays a vital role in “family cohesion, adaptability, and communication” (Zabriskie \& McCormick, 2001, p. 282). There is a positive relationship between family leisure involvement and family functioning when measured from the perspectives of a child, a parent, and the family (Zabriskie, 2000). According to Shaw (1999), parents view family leisure as an occasion for increased family functioning in the areas of communication, bonding, child development, and learning. In fact, a "significant positive relationship between family leisure involvement and family functioning” (Freeman \& Zabriskie, 2003, p. 86) has been found in families with adopted children of color. These families indicate that family leisure involvement in every day, low cost, accessible, home-based activities are the most powerful predictor of family functioning (Freeman \& Zabriskie, 2003). Furthermore, one study found families who participate in challenging outdoor recreation have reduced levels of conflict because they are more willing to work together through disagreements and problems; this is a result of increased trust, support, kindness, affection, interaction, and communication (Huff, Widmer, McCoy, \& Hill, 2003).

Until recently, however, scholars stated that "the nature of the relationship (between family leisure and aspects of family functioning) (was) still poorly understood” (Freeman \& Zabriskie, 2003, p. 75). One of the weaknesses in early research was that married couples were examined and then the findings were generalized to the entire family. Another problem involved leisure being “operationalized in a simplistic and 
Family Leisure and Functioning 13

inconsistent manner. Measurement has included any time spent together, as well as lists of activities placed into categories with no theoretical basis” (Zabriskie \& McCormick, 2001, p. 283). The lack of theoretical framework in early research resulted in “idiosyncrasies of the investigation at hand” (Orthner \& Mancini, 1991, p. 299). This has been recognized by other scholars and a call for more theory based research has resulted (Hawks, 1991; Holman, \& Epperson, 1989; Orthner \& Mancini, 1990). “It is imperative to identify and test theoretical models of family leisure that could provide the basis for strengthening measurement, generating hypotheses, and interpreting results when examining family leisure” (Zabriskie \& McCormick, 2001, p. 283).

The relationship between family functioning and family leisure can be examined using the family systems theoretical perspective (Orthner \& Mancini, 1991). The family systems theory focuses on family dynamics, which include power, relations, structures, boundaries, communications patterns, and roles (Rothbaum, Rosen, Ujiie, \& Uchida, 2002). Using this framework, family behavior can be understood by viewing the family as a unit rather than as individual parts. Changes in individuals affect the family system's behavior as a whole, just as changes in the system affect each individual family member's behavior (White \& Klein, 2002). Zabriskie and McCormick (2001) summarize the family systems theory by referring to Klein and White's (1996) work. They state that the family systems theory "holds that families are goal directed, self-correcting, dynamic, interconnected systems that both affect and are affected by their environment and by qualities within the family system itself” (p. 281). 


\section{Family Leisure and Functioning}

Olson’s (1993) Circumplex Model of Marital and Family Systems is a well established model commonly used to describe the family systems framework. This model was developed to bridge the gap between research, theory, and practice (Olson, 1993). McCormick and Zabriskie (2001) suggest that all three dimensions of Olson’s (1986) Circumplex Model (cohesion, adaptability, and communication) are facilitated through family leisure involvement. They provided preliminary evidence to support the use of the Core and Balance Model of Family Functioning for exploring family leisure relationships (Zabriskie, 2000). “Both core and balance leisure patterns (are) significantly related to family cohesion and adaptability” (p. 286). This model is grounded in the family systems theory and implies a direct relationship between family leisure patterns and family cohesion and adaptability (Zabriskie \& Freeman, 2004).

\section{Core and Balance Model of Family Leisure Functioning}

The Core and Balance Model of Family Functioning has been used frequently in recent research addressing family leisure and family functioning (Freeman \& Zabriskie, 2003; Zabriskie, 2000, 2001; Zabriskie \& Freeman, 2004; Zabriskie \& McCormick, 2001, 2003). Researchers using this model have continually found a positive relationship between family leisure involvement and successful family functioning (Zabriskie \& McCormick, 2001).The Core and Balance Model combines Iso-Ahola's (1984) idea of a need for both stability and change with Kelly's (1999) idea of two different styles of leisure behavior. Iso-Ahola (1984) stated that individuals have a tendency to "seek both stability and change, structure and variety, and familiarity and novelty in one's leisure” (p. 98). People meet their needs for stability and change through their leisure activities 
(Zabriskie \& Freeman, 2004). According to Kelly (1996, 1999), individuals try to obtain two different styles or patterns of leisure behavior throughout their life. In one style, leisure is consistent, accessible, and persisted in throughout the life course and in the other leisure has variety, is less accessible, and changes throughout the life course. These concepts concerning leisure behaviors for individuals also apply to families. Zabriskie and Freeman (2004) claim, according to the systems theory, in order for a family to function effectively, it "must meet the need for stability in interactions, structure, and relationships, as well as a need for novelty in experience, input, and challenge” (p. 54). Families as well as individuals use leisure to create the balance between stability and change.

The Core and Balance Model of Family Leisure Functioning identifies two basic categories of leisure patterns; core and balance. Core and balance leisure patterns meet the need for stability and change within a family system (Zabriskie \& McCormick, 2001). Core activities are usually common, participated in frequently (every day), low cost, home based, require little planning, and are spontaneous. These activities aid family members in forming cohesion and closeness (Zabriskie \& Freeman, 2004). Balance activities, on the other hand, are less common, require more time, effort, money, and planning, and are longer in duration. These activities provide opportunities for novelty and unpredictability resulting in family adaptation and negotiation (Zabriskie \& Freeman, 2004). Olson (1986) suggests that a balance between family cohesion and adaptability is a key element for healthy functioning families. According to this model, as family leisure participation increases, family functioning should also increase. 


\section{Family Leisure and Functioning}

Findings among traditional families as well as various known group studies consistently support the Core and Balance Model of Family Leisure Functioning (Smith et al., 2004; Zabriskie, 2000; Zabriskie \& Freeman, 2004; Zabriskie \& McCormick, 2001, 2003). The Core and Balance Model appears to offer a sound theoretical framework from which to examine family leisure functioning among families that include children with developmental disabilities. It suggests that if such families function at similar levels as families without children with disabilities as the literature suggests (Cahill \& Glidden, 1996; Ferguson, 2002), then there will be a similar relationship with family leisure involvement as well.

Recently, a number of studies examining family leisure among families with children with developmental disabilities have emerged (Mactavish \& Schleien, 1997, 1998, 2004; Scholl et al., 2003) indicating that family leisure involvement is important for the successful functioning of these families, yet broader, more representative samples are a vital step to further this line of research. Mactavish and Schleien (2004) declare that "recreation in families that include children with developmental disabilities is a neglected area of research in both disability studies and leisure studies” (p. 125). Further research along these lines would "improve understanding of family life, factors that contribute to effective family functioning, and the role of leisure in this process” (Mactavish \& Schleien, 2004, p. 125).

Adding to this line of research with the framework of family leisure functioning strengthens the foundation previous researchers have established and provides findings from a larger sample of families with children with disabilities. Findings from this study 
Family Leisure and Functioning 17

have considerable implications for families with children with developmental disabilities, professionals, services, and agencies that work with these families, and may provide direction for those families within this category who may be struggling under their high levels of demand and stress. Therefore, the purpose of this study was to examine the contribution of family leisure involvement to the family functioning of families with children with developmental disabilities.

Hypothesis 1. No relationship will be found between family leisure involvement and family functioning among families that include children with developmental disabilities after adjusting for the level of support needed by the child with a disability.

Hypothesis 2. No relationship will be found between core family leisure patterns and family cohesion after adjusting for the level of support needed by the child with a disability.

Hypothesis 3. No relationship will be found between balance family leisure patterns and family adaptability after adjusting for the level of support needed by the child with a disability.

Hypothesis 4. A difference in levels of family functioning and family leisure involvement between families with a child with a disability and a previously collected sample of families who do not have a child with a disability will be found.

Methods

Sample

The sample used in this study consisted of families of children with developmental disabilities. A developmental disability was defined as "a severe and 


\section{Family Leisure and Functioning}

chronic disorder involving mental and/or physical impairment that originates before age 22” (Mactavish et al., 1997, p. 26). The participants were recruited through one of three associations: The Arc of United States, Texas Council for Developmental Disabilities, and the National Down Syndrome Society. The Arc of United States, a national organization for people with mental retardation, posted the URL for the online questionnaire on their website and on a listserv in collaboration with the National Down Syndrome Society. The Texas Council for Developmental Disabilities, a 27-member board, dedicated to ensuring that Texans with developmental disabilities have equal opportunities, also posted the URL in their newsletter. The results cannot be generalized to all families with children who have developmental disabilities, but can only reflect the families who participated in this study. "Scholars have called (for) studies . . . to go beyond a parent only perspective and examine a child's perspective of family functioning as well” (Zabriskie \& Freeman, 2004, p. 57). In an attempt to obtain a family perspective, data was collected from one parent and one sibling (ages 10-17) without a disability. In families that did not have a sibling, just one parent's perspective was obtained. The restricted age range was implemented to involve children at a cognitive developmental level which enabled them to correctly understand and complete the survey instrument (Zabriskie \& McCormick, 2003). The URL of the online questionnaire which included consent and confidentiality information was available for participants to complete at their convenience, from July-October, 2006. The completed questionnaires were e-mailed to the researcher and stored in an online database. 
Family Leisure and Functioning 19

The sample included 62 youth and 154 parents. The youth were predominantly white (82.3\%) and male (63\%), and ranged in age from 10-17 $(M=13.15, S D=2.318)$. The parents were predominantly white (79.9\%) and female (89\%), and ranged in age from 26 to $73(M=43.96, S D=8.305)$. The majority of the parents were married (81.8\%) and only 31.8\% had ever been divorced. The family sizes ranged from 2 to 14, with an average size of 4.55 members $(S D=1.696)$. Respondents participated from 35 different states spread fairly even across the nation from the South (25\%), West (23\%), East (18\%), South West (16\%), Mid West (16\%), Hawaii (1\%) and Canada (1\%). The majority (71.4\%) of the participants lived in urban / suburban $(>50,000)$ areas and the household incomes ranged from less than $\$ 10,000$ to over $\$ 150,000$. The modal annual income category for families was $\$ 50,000$ - \$59,000 (15.6\%), with 62\% making from $\$ 40,000-\$ 99,000$.

Each of the parent participants had at least one child with a developmental disability living in their home. These children ranged in age from 1 to $40(M=13.15, S D$ $=2.318$ ) and most had been in their families for more than nine years (70.1\%). Primary diagnoses included autism (23.4\%), down syndrome (20.8\%), mental retardation (16.9\%), cerebral palsy (9.7\%), aspergers (9.1\%), attention deficit hyperactivity disorder (3.2\%), and pervasive developmental disorder - NOS (2.6\%). The other $14.3 \%$ included 11q syndrome, angelman syndrome, behavioral disorders, auditory and visual impairments, brain abnormalities, brain tumor, dyslexia, fetal alcohol spectrum disorder, genetic systemic neurologic and metabolic syndrome, global developmental delay, hemiplegia, mitochondrial disorder, oral facial digital syndrome, prematurity, rett 


\section{Family Leisure and Functioning}

syndrome, seizure disorder, soto syndrome, spina bifida, trisomy 18, undiagnosed delay, and Velo-Cardio-Facial Syndrome. Nearly half (49.4\%) of the children had additional diagnoses which included (but were not limited to) such things as attention deficit hyperactivity disorder, aspergers, auditory processing disorder, Beckwith-Weidman Syndrome, bi-polar, blindness, cerebral palsy, deafness, depression, fetal alcohol syndrome, explosive disorder, scoliosis, mental retardation, pervasive developmental disorder, seizure disorder, and sensory integration disorder. The majority of the children (49.2\%) had an IQ of less than $70,(13.6 \%<25,4.5 \%=25-40,14.9 \%=40-55,16.2 \%$ $=55-70$ ) with another 33.8\% that were unknown. The level of support needed by the children to participate in natural environments ranged from a 1 to 4 ( 1 = intermittent, $2=$ limited, 3 = extensive, 4 = pervasive $)$ with a mean of $2.52(S D=0.79)$. The modal support level was 2.18 with $44.8 \%$ ranging from 2.0 - 2.9 (limited). Intermittent to limited support was needed by $24.7 \%$ of the children; limited to extensive support was needed by $44.8 \%$ of the children, and extensive to pervasive support was needed by $30.5 \%$ of the children.

\section{Instrumentation}

The research instrument included three sections: Family Adaptability and Cohesion Scales (FACES II), used to measure family functioning (Olson et al., 1992), Family Leisure Activity Profile (FLAP), used to measure family leisure involvement (Zabriskie \& McCormick, 2001), and relevant socio-demographic questions including a scale adapted by Dyches (2000) to measure the level of support needed by people with developmental disabilities. 
Family Leisure and Functioning 21

FACES II. The Family Adaptability and Cohesion Scales (FACES II) is a 30-item scale measuring the perceptions of family cohesion and adaptability that determine family functioning based on Olson’s Circumplex Model (Olson, 1986). This scale contains 16 questions measuring cohesion and 14 questions measuring adaptability. Because it was designed to measure family dynamics, it focuses on system characteristics of family members presently living at home. This instrument uses a Likert scale ranging from 1 (almost never) to 5 (almost always). After obtaining total cohesion and adaptability scores, linear scoring interpretation procedures (Olson et al., 1992) were used to obtain the family type score which was used as an indicator of overall family functioning. The FACES II scale has acceptable psychometric properties of validity and reliability (Olson et al.). For this sample Cronbach Alpha coefficients were .78 and .79 for adaptability and .86 and .88 for cohesion.

FLAP. The Family Leisure Activity Profile (FLAP) is an activity inventory which measures family leisure involvement based on the Core and Balance Model of Family Leisure Functioning (Zabriskie, 2000). Participants identify activities performed with family members across 16 activity categories. Eight questions represent core family leisure patterns and the other eight represent balance family leisure patterns. Each question asks if the respondent participates in the activity with family members. If the answer is yes, the respondent is then asked the estimated frequency and duration for the activity. An index score was completed for each question by multiplying duration by frequency. The total core and balance index scores were found and then the total family leisure scores were calculated by summing the core and balance index scores (Zabriskie 


\section{Family Leisure and Functioning}

\& McCormick, 2001). The FLAP has acceptable psychometric properties. It has been shown to have construct and content validity, inter-rater reliability, and test-retest reliability for core $(r=.74)$, balance $(r=.78)$, and total family leisure involvement $(r=$ .78) (Zabriskie, 2001).

Demographics. Socio-demographic questions were included to determine underlying characteristics of the sample. Items included age, gender, marital status, ethnicity, state of residence, annual family income, family size, length of time the child with a developmental disability had been in the family, their IQ, diagnosis, and needed levels of support. Categorical variables were dummy coded and continuous variables were used as they were.

The level of support needed by the child with a developmental disability was determined using a scale adapted by Dyches (2000). This scale was created based on the definition, classification, and systems of support manual of the American Association on Mental Retardation (1992). The scale consists of 11 questions asking the child's skill level for various adaptive skills. For each of the 11 adaptive skills, parents chose from four levels of support: intermittent, limited, extensive, or pervasive. Intermittent support is given “on an 'as-needed' basis, is temporary, infrequent or short-termed, and is needed in few settings. Limited support is provided on a regular basis for a short period of time, in several settings. Extensive support is needed regularly in several settings and may extend over long periods of time. Pervasive support is constant and intense in all settings and may be life-sustaining” (Dyches, Cichella, Olsen, \& Mandleco, 2004, p. 175). This scale has been used successfully in past studies (Dyches et al.) and has content validity in 
Family Leisure and Functioning 23

that it covers not only the seven areas of major life activities from the developmental disability definition used in this study, but also goes beyond this definition to measure additional areas.

Analysis

The analyses of the data were performed using the statistical packages SAS and SPSS. Descriptive statistics were used to explore the underlying characteristics of the research variables. In order to gain a family perspective, three data sets were compiled: responses of parents, responses of the youth, and family responses. For each of the three data sets, scores were calculated for core, balance, total family leisure, family adaptability, family cohesion, and total family functioning. In order to make a comparison between the sample of families including a child with a disability and a sample of normative families, data from a recent study examining leisure involvement and family functioning among single and dual parent families (Hornberger, 2007) was used. Hornberger collected a national sample $(n=343)$ of parents and their dependent youth and used the same instrumentation as was used in this study. Multiple independent sample t-tests were run to examine differences between Hornberger’s (2007) sample and the sample from this study. Because numerous t-tests were run, the Bonferroni adjustment was used.

Product Moment zero-order correlations were calculated to check for multicollinearity and significant relationships among the variables. The independent variables were examined and although there were some significant zero-order correlations, they did not indicate multicollinearity (Tabachnick \& Fidell, 1996). A small 


\section{Family Leisure and Functioning}

number of significant correlations were found in each of the three data sets (parent, youth, and family). These significant independent variables as well as other sociodemographic variables believed to be theoretically correlated to the dependent variables were included in multiple regression models as controlling factors. This was done in order to examine the unique contributions of family leisure involvement to family functioning.

Multiple regression analyses were performed on each of the three dependent variables (family cohesion, family adaptability, and family functioning) for each of the three data sets (parent, youth, and family). Using the block entry method, the sociodemographic variables were entered in the first block and the family leisure variables (core and balance) were entered in the second block. The models were then examined at an alpha level of .05. In the significant models, the standardized regression coefficient (Beta) indicated the contribution of each variable.

\section{Results}

The parent cohesion scores ranged from 19 to 78 with a mean of $62.47(S D=$ 10.08); parent adaptability scores ranged from 25 to 61 with a mean of $46.47(S D=7.21)$, and parent family functioning scores ranged from 1 to 7.5 with a mean of $4.88(S D=$ 1.61). The youth cohesion scores ranged from 33 to 79 with a mean of $58.18(S D=$ 10.43); youth adaptability scores ranged from 20 to 62 with a mean of $42.32(S D=8.93)$, and youth family functioning scores ranged from 1 to 7.50 with a mean of $4.0(S D=$ 1.69). These scores fell within the established norms for FACES as determined by Olson et al. (1992). The cohesion scores of the family sample ranged from 41 to 78.5 with a 
Family Leisure and Functioning 25

mean of $60.40(S D=8.94)$; their adaptability scores ranged from 27 to 60.50 with a mean of 44.15 ( $S D=6.83$ ), and the family functioning score for the family sample ranged from 2 to 7.5 with a mean of $4.41(S D=1.47)$.

The scores of core family leisure involvement from the parent perspective ranged from 0 to 110 with a mean of $42.21(S D=16.12)$; parent balance family leisure involvement scores ranged from 0 to 131 with a mean of $50.95(S D=25.28)$, and parent total family leisure involvement scores ranged from 0 to 203 with a mean of 93.17 ( $S D=$ 36.91). The scores from the youth perspective for core family leisure involvement ranged from 11 to 116 with a mean of $42.97(S D=21.39)$; youth balance family leisure involvement scores ranged from 0 to 133 with a mean of $53.67(S D=26.86)$, and youth total family leisure involvement scores ranged from 16 to 224 with a mean of 96.83 (SD $=42.51$ ). The scores from the family perspective for core family leisure involvement ranged from 12 to 93 with a mean of $44.16(S D=16.62)$; the balance family leisure involvement from the family perspective ranged from 18.5 to 119.5 with a mean of 52.93 $(S D=22.80)$, and the total family leisure involvement from the family perspective ranged from 40 to 185 with a mean of $97.65(S D=35.10)$.

The comparison of family cohesion, family adaptability, and family functioning between the present sample of families including a child with a developmental disability and a sample of normative families indicated that there were no significant differences ( $p$ $<.01$ ) between the mean scores in the two data sets from the parent, youth or family perspective (Table 1). In comparing the leisure involvement scores (core, balance, and total leisure involvement) of the two samples (Table 2), no significant differences ( $p<$ 


\section{Family Leisure and Functioning}

.01) were found in any of the other leisure involvement scores (core, balance, and total family leisure) from all perspectives (parent, youth, and family).

A total of 18 t-tests were completed and then used in comparing the sample of families including a child with a developmental disability to the normative sample. If a $p$ $<.05$ level of confidence were used for each test it would be expected that on average, one out of 18 tests would show up to be significant by chance alone (Ramsey \& Schafer, 2002). Because one test (core leisure from the parent perspective) did show up as significant, it could have been by chance alone. Use of the Bonferroni adjustment typically prevents this possible error. The core leisure involvement, from the parent perspective, that showed up as the only significant difference between the two samples (Table 2) at the .05 level would no longer be significant using the conservative nature of the Bonferroni adjustment $(p<.01)$. Therefore using the Bonferroni adjustment there were no significant differences between the sample of families including children with disabilities and the normative sample in their leisure involvement and family functioning.

Zero-order correlations were produced to analyze the relationships between family leisure involvement and family functioning at the univariate level. Results from the parent data set (Table 3) indicated that there were relationships $(p<.001)$ between the family leisure involvement and family functioning variables. Examination of the youth data set (Table 4) indicated significant correlations between core leisure involvement and family cohesion $(r=.349, p=<.006)$, and adaptability $(r=.420, p=<.001)$, but there were no significant correlations between balance leisure involvement and the family functioning variables. Total family leisure involvement was correlated to family 
Family Leisure and Functioning 27

adaptability ( $r=.262, p=.045)$ and to total family functioning $(r=.256, p=.050)$ from the youth perspective. The length of time that the child with the developmental disability had been in the family was negatively correlated to family cohesion $(r=-.252, p=.048)$ for the youth perspective, but no significant correlations were found between the level of support needed by the child with a disability and any of the research variables from any of the perspectives. Similar to the youth data set, findings from the family data set (Table 5) indicated significant correlations between core leisure involvement and the family functioning variables, but not between balance leisure involvement and family functioning variables.

After running the zero-order correlations, the block method multiple regression analyses were computed to examine the relationship between family leisure involvement and family functioning at the multivariate level. For each of the data sets (parent, youth, and family), a multiple regression model was created for each of the dependent variables (family cohesion, family adaptability, and total family functioning), resulting in a total of nine multiple regression models. Independent variables were included in the regression models if they had significant zero-order correlations to the dependent variables or if they were theoretically justified to be included based on past literature.

In the parent sample (Table 6), family cohesion was regressed on the independent variables of parent age, level of support needed by the child with a developmental disability, amount of time the child with the disability had been in the family, parent ethnicity, core leisure involvement, and balance leisure involvement. The first block contained only the socio-demographic variables, and it explained a small, but statistically 


\section{Family Leisure and Functioning}

significant amount of the variance in family cohesion $\left(r^{2}=.066, p=.042\right)$. The level of support needed by the child with the disability was a significant negative predictor $(\beta=$ $.210, p=.014)$. After adding core and balance family leisure involvement into the second block there was a statistically significant change in the variance explained by the model $\left(\Delta R^{2}=.156, p<.001\right)$. Core family leisure involvement was a significant predictor of family cohesion $(\beta=.379, p<.001)$, while the level of support needed by the child with the disability was no longer significant $(\beta=-.156, p=.050)$.

In the parent sample (Table 7), family adaptability was regressed on the independent variables of level of support needed by the child with the disability, parent ethnicity, age of the child with the disability, family size, core family leisure involvement, and balance family leisure involvement. The first block contained only the socio-demographic variables, and the model explained a significant but small amount of the variance in family adaptability $\left(r^{2}=.079, p=.015\right)$. In the first block, the level of support needed by the child with the disability was a significant negative predictor $(\beta=$ $.184, p=.030)$ as well as the parent ethnicity $(\beta=-.166, p=.042)$. After adding the core and balance family leisure involvement variables into the second block there was a significant change in the model $\left(\Delta R^{2}=.116, p<.001\right)$. Core family leisure involvement was a significant predictor of family adaptability $(\beta=.630, p<.001)$, while the level of support needed by the child with the disability was no longer significant $(\beta=-.121, p=$ $.135)$.

In the final model for the parent data (Table 8), family functioning was regressed on the independent variables of parent age, level of support needed by the child with the 
Family Leisure and Functioning 29

disability, core family leisure involvement, and balance family leisure involvement. The first block contained only the socio-demographic variable, and it did not explain a significant portion of the variance in family functioning $\left(r^{2}=.032, p=.090\right)$. After adding core and balance family leisure involvement into the second block there was a statistically significant change in the variance explained by the model $\left(\Delta R^{2}=.176, p<\right.$ .001). Core family leisure involvement was once again a significant predictor of family functioning $(\beta=.380, p<.001)$.

In the youth sample (Table 9), family cohesion was regressed on the independent variables of level of support needed by the child with the disability, core family leisure involvement, and balance family leisure involvement. The first block contained only the socio-demographic variable, and it did not explain a significant portion of the variance in family cohesion $\left(r^{2}=.013, p=.396\right)$. After adding core and balance family leisure involvement into the second block there was a statistically significant change in the variance explained by the model $\left(\Delta R^{2}=.114, p=.034\right)$. Once again, core leisure involvement was the only significant predictor of family cohesion $(\beta=.399, p=.010)$. In the youth sample (Table 10), family adaptability was regressed on the independent variables of level of support needed by the child with the disability, youth age, length of time the child with the disability had been in the home, income, parent history of divorce, core family leisure involvement, and balance family leisure involvement. The first block contained only the socio-demographic variable, and it did not explain a significant portion of the variance in family adaptability $\left(r^{2}=.062, p=\right.$ .623). After adding core and balance family leisure involvement into the second block 


\section{Family Leisure and Functioning}

there was a statistically significant change in the variance explained by the model $\left(\Delta R^{2}=\right.$ $.168, p=.006)$. Core family leisure involvement was the only significant predictor of family adaptability $(\beta=.465, p=.003)$.

In the youth sample (Table 11), family functioning was regressed on the independent variables of level of support needed by the child with the disability, youth age, length of time the child with the disability had been in the home, income, parent history of divorce, core family leisure involvement, and balance family leisure involvement. The first block contained only the socio-demographic variable, and it did not explain a significant portion of the variance in family functioning $\left(r^{2}=.100, p=\right.$ .330). After adding core and balance family leisure involvement into the second block there was a statistically significant change in the variance explained by the model $\left(\Delta R^{2}=\right.$ $.134, p=.016$ ) and core family leisure involvement was again the only significant predictor of family functioning $(\beta=.406, p=.008)$.

The final series of multiple regression analyses examined family cohesion, family adaptability, and family functioning from the family perspective. In the family sample (Table 12) family cohesion was regressed on the independent variables of the level of support needed by the child with a disability, parent history of divorce, income, youth age, core family leisure involvement, and balance family leisure involvement. The first block contained only the socio-demographic variable, and it did not explain a significant portion of the variance in family cohesion $\left(r^{2}=.137, p=.088\right)$. After adding core and balance family leisure involvement into the second block there was a statistically significant change in the variance explained by the model $\left(\Delta R^{2}=.202, p=.001\right)$. Core 
Family Leisure and Functioning 31

family leisure involvement was the only significant predictor of family cohesion $(\beta=$ $.536, p<.001)$.

In the family sample (Table 13), family adaptability was regressed on the independent variables of the level of support needed by the child with a disability, parent history of divorce, income, youth age, core family leisure involvement, and balance family leisure involvement. Again the first block contained only the socio-demographic variable, and it did not explain a significant portion of the variance in family adaptability $\left(r^{2}=.013, p=.945\right)$. After adding core and balance family leisure involvement into the second block there was a statistically significant change in the variance explained by the model $\left(\Delta R^{2}=.226, p=.001\right)$. Core family leisure involvement was the only significant predictor of family adaptability $(\beta=.579, p<.001)$.

In the family sample (Table 14), family functioning was regressed on the independent variables of level of support needed by the child with a disability, parent history of divorce, income, youth age, core family leisure involvement, and balance family leisure involvement. The first block contained only the socio-demographic variable, and it did not explain a significant portion of the variance in family functioning $\left(r^{2}=.074, p=.374\right)$. After adding core and balance family leisure involvement into the second block, there was a statistically significant change in the variance explained by the model $\left(\Delta R^{2}=.237, p<.001\right)$. Core family leisure involvement was the only significant predictor of family functioning $(\beta=.585, p<.001)$. 
32 Family Leisure and Functioning

\section{Discussion}

The purpose of this study was to examine the contribution of family leisure involvement to family functioning among families of children with developmental disabilities. It was also hypothesized that in comparing this sample of families to a sample of normative families there would be no significant differences in their levels of family functioning and family leisure involvement. Findings supported this hypothesis and indicated that there were no significant differences in family leisure involvement and family functioning among the two samples. Results also provided new insight into the hypothesized relationship between family leisure involvement and family functioning among families with children with developmental disabilities from this sample. A significant positive relationship was found between core family leisure involvement and family functioning variables. Interestingly, findings did not indicate a significant relationship between balance leisure involvement and family functioning variables. Core and balance leisure involvement did not contribute equally to family functioning among this sample of families that include a child with a developmental disability. These findings provide specific implications for parents and professionals who work with families of children with developmental disabilities such as therapeutic recreation specialists, social workers, teachers, clubs, and organizations.

\section{Comparison of Families of a Child with a Disability to Normative Families}

Traditionally researchers suggested that children with disabilities damaged their families and created a high degree of pathology in their family functioning resulting in disabled families (Ferguson, 2002; Glidden, 1993). Because these families reported 
Family Leisure and Functioning 33

increased pressure and demands along with added stress and challenges (Dyson, 1996; Fuller \& Rankin, 1994; Mactavish et al., 1997), it was assumed that they were lower functioning. More recent research has reported mixed results for family functioning in families that include a child with a disability (Summers et al., 2005). Some reported these families as malfunctioning (Kronick, 1976) and deviating from the normal range of family cohesion and adaptability (Michaels \& Lewandowski, 1990) while others reported their adaptational profiles resembled, in range and number, those profiles of families with children without disabilities (Baxter et al., 1995; Krauss \& Seltzer, 1993). The most recent research agrees that families of children with disabilities adjust positively and cope effectively with the added demands of raising a child with a developmental disability (Blacher, 2001; Ferguson, 2002; Taunt \& Haustings, 2002). Therefore, it has been argued that families with children who have disabilities function at or near normal levels based on established norms for families in general (Cahill \& Glidden, 1996).

Current findings provide further support to the recent research that suggests families with children with disabilities function at similar levels to normative families. Findings indicated that for this sample, families including a child with a developmental disability reported nearly equal perceptions of family adaptability, family cohesion, and overall family functioning as a sample of normative families collected during the same time frame. Using the Bonferroni adjustment, which takes into account results showing up by chance alone, families also reported nearly identical levels of family leisure involvement in core, balance, and total family leisure. 


\section{Family Leisure and Functioning}

Such findings not only provide further evidence supporting similarities in aspects of family functioning between these two family types, but they extend beyond the present literature in several ways. First, most previous studies made general comparisons to nationally established norms and were not able to make direct comparisons between samples. Therefore, this is one of the first studies to utilize statistical methods to report no significant differences between families that include a child with a disability and normative families. Second, the current study was one of the first to utilize a specific measure of overall family functioning in this comparison. By using the linear scoring method recommended by Olson et al. (1992), this study reported no differences in family cohesion, family adaptability, and overall family functioning. Furthermore, this study answered calls to go beyond the parent only perspective when examining family variables and reported consistent findings from parent, child, and family perspectives. Finally, results also extend beyond previous work by examining behavioral characteristics related to aspects of family functioning. The Core and Balance Model suggests direct relationships between family leisure involvement and family functioning. Therefore, the findings that indicate no differences in levels of core or balance family leisure involvement provide further support for the similarities in family functioning between normative families and those including a child with a disability.

\section{Family Leisure Involvement and Family Functioning}

Researchers have consistently found positive relationships between family leisure involvement and positive family functioning for families in general (Hawks, 1991; Holman \& Epperson, 1989; Orthner \& Mancini, 1991; Zabriskie \& McCormick, 2001). 
Family Leisure and Functioning 35

Freeman and Zabriskie (2003) found specifically that families with adopted children of color indicated family leisure involvement in core family leisure activities was the most powerful predictor of family functioning. Additional known group studies examining the relationship between family leisure involvement and family functioning have been completed. Some of these include Hispanic families (Christenson et al., 2006), and single parent families (Smith et al., 2004). These have also all found similar results. Researchers (Freeman \& Zabriskie, 2003; Zabriskie, 2000, 2001; Zabriskie \& Freeman, 2004; Zabriskie \& McCormick, 2001, 2003) have called for further known group studies of different family types including families with children with developmental disabilities. Recently, a number of studies examining family leisure among families of children with developmental disabilities have emerged (Mactavish \& Schleien, 1997, 1998, 2004; Scholl et al., 2003) indicating that family leisure involvement is important for the successful functioning of these families. This line of research is fairly new and as with most research in the beginning stages, researchers (Mactavish \& Schleien, 1997, 2004; Mactavish et al., 1997; Scholl et al.) have mainly used qualitative research methods with rather small sample sizes. Although this is a necessary beginning step, broader more representative samples were needed as well as additional studies using quantitative research methods. This study was a starting point for meeting those needs.

This study addressed the call for improved understanding of "family life, factors that contribute to effective family functioning, and the role of leisure in this process" (Mactavish \& Schleien, 2004, p. 125). By obtaining a broader more representative sample and by using quantitative research methods this study has gone beyond previous research 


\section{Family Leisure and Functioning}

in order to obtain new and insightful information that both supports and adds to the present body of knowledge concerning families with children with developmental disabilities and the benefits of family leisure for them.

Findings from this study indicate that a positive multivariate relationship exists between core leisure involvement and family functioning for this sample from the parent $(p<.01)$, youth $(p<.01)$, and family perspective $(p<.01)$. Core leisure activities are common, low-cost, home-based, spontaneous, informal, participated in frequently, and require little planning. Even when taking into account other family characteristics such as level of support needed by the child with the disability, time the child has been in the home, income, history of divorce, age, ethnicity, and family size, the only significant predictor of higher family functioning was specifically core family leisure involvement. In other words, families who participate in board games, home meals, gardening, shooting hoops, and reading books, etc. had higher levels of family functioning. This sheds some new light on the relationship between specific types of leisure involvement and family functioning for these families as compared to families in general. Core and balance leisure involvement do not have the same relationship with family functioning for these families.

Previous research (Freeman \& Zabriskie, 2003; Hill, Freeman, \& Huff, 2001; Smith et al., 2004; Zabriskie \& McCormick, 2001) has found that both core and balance leisure involvement are important for youth and parents in their perception of family functioning. Responses from a youth perspective have consistently reported core family leisure involvement to be a greater contributor to the explanation of family functioning 
Family Leisure and Functioning 37

than balance family leisure involvement. This has been found from a child perspective, in a variety of family structures including families with adoptive children of color (Freeman and Zabriskie, 2003; Zabriskie \& Freeman, 2004), Hispanic families (Christenson, Zabriskie, Eggett, \& Freeman, 2006), and single parent families (Smith, Taylor, Hill, \& Zabriskie, 2004). From the parent perspective, however, findings have indicated core and balance leisure involvement to be equally significant in predicting family cohesion and adaptability. Findings from the present study indicated, for the first time within this line of research, that from the parent perspective, core leisure involvement alone was the only significant predictor of family cohesion, family adaptability, and total family functioning. In fact, it was the only significant predictor of family functioning from all three perspectives (parent, youth, and family). It seems that particularly for this sample of families, core leisure involvement plays an essential role in their family functioning. Although the findings indicate that core leisure involvement was the only significant predictor of family functioning in families that include children with developmental disabilities, one must question if this relationship would subsist if balance leisure involvement was eliminated. Although core leisure stands out for these families, it must be acknowledged that they did participate in balance leisure. These families participated in the same levels of balance activities as normative families, even though these activities may have been more difficult for them. In other words, these families are likely to have made substantial effort to negotiate their individual constraints in order to participate in balance leisure activities. The model suggests that both core and balance 


\section{Family Leisure and Functioning}

leisure involvement are interrelated and that both are needed for healthy family functioning, so balance leisure within these families should not be undervalued.

It is likely that the very nature of having a child with a disability requires families to develop the adaptive skills necessary for healthy family functioning. These skills are most likely learned by families in the early stages of a child's life as the families learn to accept and negotiate the constraints and challenges they encounter in having a child with a disability. Therefore, just as normative families develop adaptive skills through balance leisure involvement; families of children with developmental disabilities may develop their adaptive skills through other venues. If these families already have adaptive skills then involvement in balance leisure may not contribute to the explanation of variance in their family functioning at the same level as it does for normative families.

Although families that include a child with a disability face added demands, stress, and constraints (Scholl et al., 2003; Singer, 2002), those in this sample participated in the same levels of balance leisure activities when compared to a sample of normative families. This is interesting because balance leisure activities usually take place away from home, are longer in duration, require more planning, time, and effort, and are more expensive, and as such they may require more from these families, and add additional stress, and demands on them. This is one reason why it is intriguing that these families participated in normal levels of balance leisure. Core leisure activities, on the other hand, are common, everyday, require little planning, and are usually home based. Such activities may be easier and more accessible for families of children with disabilities to participate in. Involvement in lower stress core family leisure activities may be more 
enjoyable, and less demanding, which may be one reason they explained significant variance in family cohesion, adaptability, and total family functioning. Although the regression models only explained $11 \%-24 \%$ of the total variance in family functioning, core leisure involvement must be considered one of the many factors contributing to healthy families including children with disabilities. These findings may be important for parents and professional who work with these families.

Although previous studies report that leisure involvement is important to families with a child with a disability (Heyne \& Schleien, 1997; Horna, 1994; Mactavish \& Schleien, 2004; Scholl et al., 2003), this study has gone beyond previous research by examining various types of leisure and the relationship each has with family functioning. After considering the leisure variables, the level of support needed by the child with a developmental disability was never found to be a factor in predicting family cohesion or adaptability. In other words, even though it was speculated that the level of support needed by the child with the disability could be related to the level of family functioning, this study found that core family leisure involvement has a much stronger relationship with family functioning than the level of support and care required by the child. The families of a child with a disability from this sample functioned at very similar levels to traditional families, and they also participated in very similar levels of family leisure. There was a direct relationship between family functioning and core family leisure involvement for these families. Results indicated that for families with a child with a disability it is not just any leisure involvement that has a positive relationship with family 


\section{Family Leisure and Functioning}

functioning, but specifically core leisure involvement (common, everyday, home-based, requiring little planning).

This study not only supported previous research that has found a positive relationship between family leisure involvement and family functioning, but also added further to the construct validity and usefulness of the Core and Balance Model. This model indicates a direct relationship between family leisure involvement and family functioning (Zabriskie \& McCormick, 2001). It supports further use of this model as a foundation for future family leisure research and implies that it can offer "the necessary framework to further test and understand the nature of the family leisure relationship” (Zabriskie \& McCormick, 2001, p. 288). It also responded to the concerns of Mactavish and Schleien (2004) when they stated that "recreation in families that include a child with developmental disabilities is a neglected area of research” (Mactavish \& Schleien, 2004, p. 125), and further research would "improve understanding of family life, factors that contribute to effective family functioning, and the role of leisure in this process” (Mactavish \& Schleien, 2004, p. 125). This study has provided further information on leisure within these families and how it contributes to their family functioning.

\section{Practical Implications}

Many implications arise, from this study for both families of children with disabilities and professionals (such as recreation therapists and social workers, etc.) who work with these families. Based on the findings, theory would suggest that core family leisure involvement is positively correlated to family functioning. It is important to recognize that core family leisure involvement may be an essential element of family life 
Family Leisure and Functioning 41

for families of children with developmental disabilities. This is the first study to identify specifically which type of family leisure is related to family functioning. It not only provides empirical evidence, but does so from both a parent and youth perspective. While balance leisure involvement is not related to family functioning for these families, it is for many other types of families.

A positive relationship was found between core family leisure involvement and family functioning. Based on the Circumplex Model, The Core and Balance Model, and The Family Systems Theory, involvement in core family leisure should improve family functioning in families that include a child with a developmental disability. Professionals, parents, and family help services could use this information to help develop the specific leisure skills needed to improve family functioning among families of children with developmental disabilities. Parents may want to consider participating in such things as board games, gardening, meals together as a family, reading together, shooting hoops, or other everyday, common, and simple activities that can be done together at home with little or no resources. It is common for therapeutic recreation programs to provide intervention focused mainly on balance activities, but this study shows that ongoing, regular, home-based leisure activities can have a greater positive influence on family functioning than balance activities. Professionals could consider teaching the required skills, informing the parents of the many options of core leisure activities, and facilitating regular participation in these home-based leisure activities.

These findings also indicate that although families face their own set of challenges and stressors, many are resilient and find ways to deal and function with them. 


\section{Family Leisure and Functioning}

Even though the families from this sample most likely face constraints and challenges as they raise their child with a disability, still this study shows that their family functioning and family leisure involvement is nearly identical to traditional families. Although it may be theorized that the functioning level of the child with a disability may have an effect on the level of family functioning, this study found that this was not so.

Additional implications from this study indicate that the Family Leisure Activity Profile (FLAP) may be used for multiple purposes. FLAP may be beneficial in providing professionals and parents with specific information as to what leisure their families are presently participating in and what possible changes or additions they can make in their leisure habits in an effort to improve their family functioning. Leisure education workshops and programs could also provide parents with added knowledge and understanding about the value of core family leisure involvement and provide a list of various core activities that could be participated in at home with the family. "Family leisure is not a magic pill or a panacea that will automatically resolve the intricate challenges and difficulties faced by. ..” families of children with developmental disabilities (Zabriskie \& Freeman, 2004, p. 75), but however, these findings imply that family involvement in core leisure activities is related to aspects of family functioning and may provide an important, inexpensive, and practical approach for improving family cohesion and family adaptability among families that include a child with a developmental disability. 
Recommendations for Future Research

Several useful implications exist from this study, but one must recognize that it does have its limitations. Core family leisure involvement seems to affect family functioning in families that include a child with a developmental disability. This must be examined further among additional and even larger samples of families of children with disabilities. Scholars should attempt to gain a more in-depth understanding of core family leisure involvement and its relationship to family functioning. Qualitative methods may be beneficial in determining the positive characteristics of core leisure involvement. It may also be important to examine relationships between specific core activities and family functioning for these families and determine if variations exist between these relationships.

This study used correlational techniques to identify relationships, and therefore causal relationships cannot be determined or assumed without further research. In order to examine the directionality of the relationship between family functioning and family leisure involvement, future research should include longitudinal studies with experimental designs. This study also had a limited sample. Although it was somewhat larger and broader than previous research examining leisure in families that include a child with a disability, still it was not a true random sample and therefore the results cannot be generalized to all families of children with developmental disabilities. A large, randomized, national sample is recommended for use in future studies which would allow for generalizations to a broader population. Future studies should continue to obtain a family perspective by obtaining data from multiple family members. This study had a 
44 Family Leisure and Functioning

smaller number of youth respondents than parent respondents. The lower response rate of the youth was possibly due to the lack of older children in the home, but if future studies could obtain an even larger sample then the number of youth respondents would also be greater which would provide a better understanding of the youth perspective. Finally, this is the first study providing empirical evidence that core leisure involvement is related to higher family functioning among families that include a child with a developmental disability. Therefore, it is recommended that core leisure involvement be included in future studies which address family functioning within families that include a child with a developmental disability. 


\section{References}

American Association on Mental Retardation. (1992). Mental Retardation: Definition, Classification, and Systems of Supports (9th ed.). Washington, D.C.: Author.

Baxter, C., Cummins, R. A., \& Polak, S. (1995). A longitudinal study of parental stress and support: From diagnosis of disability to leaving school. International Journal of Disability, Developmental and Education, 42, 125-136.

Blacher, J. (2001). Transition to adulthood: Mental retardation, families, and culture. American Journal on Mental Retardation, 106, 173-188.

Cahill, B. M., \& Glidden, L. M. (1996). Influence of child diagnosis on family and parental functioning: Down syndrome versus other disabilities. American Journal of Mental Retardation, 10, 149-160.

Christenson, O., Zabriskie, R., Eggett, D., \& Freeman, P. (2006). Family acculturation, family leisure involvement, and family functioning among Mexican-Americans. Journal of Leisure Research, 38(4), 475 - 495.

Dyches, T. T. (2000). Child (with special needs) description. Adapted from: American Association on Mental Retardation. (1992). Mental Retardation: Definition, Classification, and Systems of Supports (9th ed.). Washington, D.C.: Author.

Dyches, T. T., Cichella, E., Olsen, S. F., \& Mandleco, M. (2004). Snapshots of life: Perspectives of school-aged individuals with developmental disabilities. Research \& Practice for Persons with Severe Disabilities, 29(3), 172-182. 
46 Family Leisure and Functioning

Dyson, L. L. (1996). The experiences of families of children with learning disabilities: Parental stress, family functioning, and sibling self-concept. Journal of Learning Disabilities, 29(3), 280-286.

Ferguson, P. (2002). A place in the family: An historical interpretation of research on parental reactions to having a child with a disability. Journal of Special Education, 36, 126-147.

Freeman, P., \& Zabriskie, R. B. (2003). Leisure and family functioning in adoptive families: Implications for therapeutic recreation. Therapeutic Recreation Journal, 37(1), 73-93.

Fuller, G. B., \& Rankin, R. E. (1994). Differences in levels of parental stress among mothers of learning disabled, emotionally impaired, and regular school children. Perceptual and Motor Skills, 78, 583-592.

Glidden, L. M. (1993). What we do not know about families with children who have developmental disabilities: Questionnaire on resources and stress as a case study. American Journal of Mental Retardation, 97(5), 481-495.

Hawks, S. R. (1991). Recreation in the family. In S. J. Bahr (Ed.), Family research: A sixty year review, 1930-1990. New York: Lexington Books.

Heyne, L., \& Schleien, S. (1997). Teaming up with parents to support inclusive recreation. Parks \& Recreation, 32(5), 76-81.

Hill, B. J., Freeman, P. A. \& Huff, C. (2001). The influence of challenging recreation on family functioning. In M.E. Havitz \& M.F. Floyd (Eds.), Books of Abstracts: 2001 
Family Leisure and Functioning 47

Leisure Research Symposium (p. 65). Ashburn, VA: National Recreation and Park Association.

Holman, T. B., \& Epperson, A. (1989). Family and leisure: A review of the literature with research recommendations. Journal of Leisure Research, 16, 277-294.

Horna, J. (1994). The Study of Leisure: An introduction. Toronto, Ontario, Canada: Oxford University Press.

Hornberger, L. (2007). A national study of family leisure functioning among single parent families. Unpublished master's thesis, Brigham Young University, Provo, UT

Huff, C., Widmer, M., McCoy, K., \& Hill, B. (2003). The influence of challenging outdoor recreation on parent-adolescent communication. Therapeutic Recreation Journal, 37(1), 18-37.

Iso-Ahola, S. (1984). Social psychological foundations of leisure and resultant implications for leisure counseling. In E. T. Dowd (Ed.), Leisure counseling: Concepts and applications (pp. 97-125). Springfield, IL: Charles C. Thomas.

Kelly, J. R. (1996). Leisure 3rd Edition. Needham Heights, MA: Allyn \& Bacon.

Kelly, J. R. (1999). Leisure behaviors and styles: Social, economical, and cultural factors. In E. L. Jackson \& T. L. Burton (Eds.), Leisure studies: Prospects for the twentyfirst century (pp. 135-150). State College, PA: Ventura.

Klein, D. M., \& White, J. M. (1996). Family theories: An introduction. Thousand Oaks, CA: Sage.

Krauss, M. W., \& Seltzer, M. M. (1993). Current well-being and future plans of older care giving mothers. The Irish Journal of Psychology, 14(1), 48-63. 
48 Family Leisure and Functioning

Kronick, D. (1976). Three families: The effect of family dynamics on social and conceptual learning. San Rafael, CA: Academic Therapy.

Kwai-sang, M., \& Li-Tsang, C. W. P. (1999). Adjustment in adaptation in parents of children with developmental disability in two-parent families: A review of the characteristics and attributes. British Journal of Developmental Disabilities, 45, 38-51.

Landesman, S., \& Vietze, P. (Eds). (1987). Living environments and mental retardation. Washington, DC: American Association on Mental Retardation.

Mactavish, J., \& Schleien, S. (1997). Patterns of family recreation in families that include children with a developmental disability. Journal of Leisure Research, 29(1), 2126.

Mactavish, J., \& Schleien, S. (1998). Playing together growing together: Parents' perspectives on the benefits of family recreation in families that include children with a developmental disability. Therapeutic Recreation Journal, 32(3), 207-230.

Mactavish, J., \& Schleien, S. (2004). Re-injecting spontaneity and balance in family life: parents' perspective on recreation in families that include children with developmental disability. Journal of Intellectual Disability Research 48(2), 123141.

Mactavish, J., Schleien, S., \& Tabourne, C. (1997). Patterns of family recreation in families that include children with a developmental disability. Journal of Leisure Research, 29(1), 21-46. 
Family Leisure and Functioning 49

Margalit, M., \& Heiman, T. (1986). Family climate and anxiety in families with learning disabled boys. Journal of the American Academy of Child Psychiatry, 25, 841846.

Michaels, C. R., \& Lewandowskie, L. J. (1990). Psychological adjustment and family functioning of boys with learning disabilities. Journal of Learning Disabilities, 23, 446-450.

Olson, D. H. (1986). Circumplex model VII: Validation studies and FACES III. Family Process, 25, 337-351.

Olson, D. H. (1993). Circumplex model of marital and family systems: Assessing family systems. In F. Walsh (Ed.), Normal Family Processes (pp. 104-137). New York: Guilford Press.

Olson, D. H. (2000). Circumplex model of marital and family systems. Journal of Family Therapy, 22(2), 144-167.

Olson, D. H., McCubbin, H. I., Barnes, H., Larsen, A., Muxen, M., \& Wilson, M. (1992). Family inventories: Second revision. St. Paul, MN: University of Minnesota.

Olsson, M. B., \& Hwang, C. P. (2001). Depression in mothers and fathers of children with intellectual disabilities. Journal of Intellectual Disability Research, 45, 535543.

Orthner, D. K. (1998). Strengthening today’s families: A challenge to parks and recreation. Parks and Recreation, 33(3), 87-98.

Orthner, D. K., \& Mancini, J. A. (1990). Leisure impacts on family interaction and cohesion. Journal of Leisure Research, 22(2), 125-137. 
50 Family Leisure and Functioning

Orthner, D. K., \& Mancini, J. A. (1991). Benefits of leisure for family bonding. In B. L. Driver, P. J. Brown, \& G. L. Peterson (Eds.). Benefits of leisure (pp. 215-301). State College, PA: Venture.

Ramsey, F. L., \& Schafer, D. W. (2002). The statistical sleuth: A course in methods of data analysis (2nd ed.). Pacific Grove, CA: Duxbury.

Roach, M. A., Orsmond, G. I., \& Barratt, M. S. (1999). Mothers and fathers of children with Down syndrome: Parental stress and involvement in childcare. American Journal on Mental Retardation, 104(5), 422-436.

Rothbaum, F., Rosen, K., Ujiie, T., \& Uchida, N. (2002). Family systems theory, attachment theory, and culture. Family Process, 41, 328-350.

Scholl, K., McAvoy, L., Rynders, J., \& Smith, J. (2003). The influence of inclusive outdoor recreation experience on families that have a child with a disability. Therapeutic Recreation Journal, 37(1), 38-57.

Shaw, S. (1999). Purposive leisure: Examining parental discourses on family activities. In W. Stewart \& D. Sandahl (Eds.), Abstracts from the 1999 Symposium on Leisure Research (p. 7), Ashburn, VA: National Park and Recreation Association.

Singer, G. H. S. (2002). Suggestions for a pragmatic program of research on families and disability. Journal of Special Education, 36(3), 148-154.

Smith, K. M., Taylor, S., Hill, B., \& Zabriskie, R. B. (2004). Family functioning and leisure in single-parent families. Abstracts from the 2004 Leisure Research Symposium. Ashburn, VA: National Recreation and Parks Association. 
Family Leisure and Functioning 51

Summers, J., Poston, D., Turnbull, A., Marquis, J., Hoffman, L., Mannan, H., \& Wang, M. (2005). Conceptualizing and measuring family quality of life. Journal of Intellectual Disability Research, 49(10), 777-783.

Tabachnick, B. G., \& Fidell, L. S. (1996). Using multivariate statistics. California State University, Northridge: Harper Collins College Publishers.

Taunt, H., \& Hastings, R. (2002). Positive impact of children with developmental disabilities on their families: A preliminary study. Education and Training in Mental Retardation and Developmental Disabilities, 37, 410-420.

United Media Enterprises Report on Leisure in America. (1982). Where does time go? New York: United Media Enterprises.

Warfield, M., Krauss, M., Hauser-Cram, P., Upshur, C., \& Shonkoff, J. (1999). Adaptation during early childhood among mothers of children with disabilities. Developmental and Behavioral Pediatrics, 20, 9-16.

White, J. M., \& Klein, D. M. (2002). Family theories: An introduction, (2nd ed.). Thousand Oaks, CA: Sage.

Zabriskie, R. B. (2000). An examination of family and leisure behavior among families with middle school aged children. Unpublished doctoral dissertation, Indiana University, Bloomington, Indiana.

Zabriskie, R. B. (2001). Family recreation: How can we make a difference? Parks and Recreation, 36(10), 30-42.

Zabriskie, R. B., \& Freeman, P. (2004). Contributions of family leisure to family functioning among transracial adoptive families. Adoption Quarterly, 7(3), 49-77. 
52 Family Leisure and Functioning

Zabriskie, R. B., \& McCormick, B. P. (2001). The influences of family leisure patterns on perceptions of family functioning. Family Relations: Interdisciplinary Journal of Applied Family Studies, 50(3), 66-74.

Zabriskie, R. B., \& McCormick, B. P. (2003). Parent and child perspectives of family leisure involvement and satisfaction with family life. Journal of Leisure Research, 35(2), 163-189. 
Family Leisure and Functioning 53

Table 1

Differences between Families with a Child with a Developmental Disability and Normative Families on Cohesion, Adaptability, and Family Functioning

Variable

Parent Perspective

Cohesion

Adaptability

Disability $(n=154)$

Normative $(n=343)$

Disability

Normative

Family Functioning

Disability

Normative

Youth Perspective

Cohesion

Disability $(n=62)$

Normative $(n=343)$

Adaptability

Disability

Normative

Family Functioning

Disability

Normative
M

62.47

62.83

46.47

46.94

4.88

4.96

58.18

58.85

43.32

43.92

4.00

4.22

60.40

60.84

Normative $(n=343)$

Adaptability

Disability

Normative

Family Functioning

Disability

Normative
44.15

45.43

4.41

4.59
Cohesion
10.08

9.92

7.21

7.17

1.61

1.54 $\begin{array}{ll}-.542 & .588 \\ -.534 & .594\end{array}$

$-.372 \quad .710$
-.370

$-.370 \quad .712$

$\begin{array}{ll}-.663 \quad .508 \\ -.661 & .509\end{array}$

$-.661 \quad .509$ $\begin{array}{lll}10.43 & -.458 & .647\end{array}$

10.69

$-.466 \quad .642$

8.93

8.05

-1.415 .158

$-1.317 \quad .192$

1.69

$-.952 \quad .341$

$-.935 \quad .352$

$\begin{array}{lll}1.65 & -.935 & .352\end{array}$

Family Perspective 
54 Family Leisure and Functioning

Table 2

Differences between Families with a Child with a Developmental Disability and Normative Families on Family Leisure Patterns

Variable

Parent Perspective

Core Activities

Disability $(n=154)$

Normative $(n=343)$

Balance Activities

Disability

Normative

Total Family Leisure

Disability

Normative
M

42.21

45.62

50.95

50.47

93.17

96.09

42.97

42.58

Normative $(n=343)$

Balance Activities

Disability $(n=60)$

Normative $(n=343)$

Total Family Leisure

$$
\text { Disability }(n=59)
$$

Normative $(n=343)$
53.67

52.76

96.83

94.73
16.12

17.02

25.28

27.13

36.91

38.07

21.39

16.94

26.86

27.43

42.51

38.35

44.16

44.10

Disability $(n=61)$

Normative $(n=343)$

Balance Activities

Disability $(n=60)$

Normative ( $n=343)$

Total Family Leisure

Disability $(n=59)$

Normative $(n=343)$
52.93

51.52

97.65

95.41
16.62

15.75

22.80

25.85

35.10

36.89
Core Activities
-2.093.037*

$-2.137 .033 *$

$-.187 \quad .852$
-.192

$-.192 \quad .848$

$-.798 \quad .425$

$-.807 \quad .420$

Family Perspective 
Family Leisure and Functioning 55 
Table 3

Zero Order Pearson Correlations: Parent Data

\begin{tabular}{|c|c|c|c|c|c|c|c|c|c|c|c|c|}
\hline & Core & $\begin{array}{l}\text { Balanc } \\
\text { e }\end{array}$ & FLtotal & Cohes & Adapt & Famfunc & $\begin{array}{l}\text { Parent } \\
\text { age }\end{array}$ & Support & distime & P. Eth & $\begin{array}{l}\text { Youth } \\
\text { Age }\end{array}$ & $\begin{array}{l}\text { Family } \\
\text { size }\end{array}$ \\
\hline $\begin{array}{l}\text { Core } \\
p \text {-value }\end{array}$ & 1 & $\begin{array}{l}.568 \\
<.001 * \\
*\end{array}$ & $\begin{array}{l}.826 \\
<.001^{* *}\end{array}$ & $\begin{array}{l}.400 \\
<.001 * *\end{array}$ & $\begin{array}{l}.393 \\
<.001 * *\end{array}$ & $\begin{array}{l}.405 \\
<.001^{* *}\end{array}$ & $\begin{array}{l}.013 \\
.876\end{array}$ & $\begin{array}{l}-.102 \\
.207\end{array}$ & $\begin{array}{l}-.060 \\
.459\end{array}$ & $\begin{array}{l}.129 \\
.112\end{array}$ & $\begin{array}{l}.045 \\
.579\end{array}$ & $\begin{array}{l}.203 \\
.012 *\end{array}$ \\
\hline $\begin{array}{l}\text { Balance } \\
p \text {-value }\end{array}$ & & 1 & $\begin{array}{l}.933 \\
<.001 * *\end{array}$ & $\begin{array}{l}.236 \\
<.001 * *\end{array}$ & $\begin{array}{l}.248 \\
.002 * *\end{array}$ & $\begin{array}{l}.253 \\
.002 * *\end{array}$ & $\begin{array}{l}.144 \\
.079\end{array}$ & $\begin{array}{l}-.126 \\
.121\end{array}$ & $\begin{array}{l}.050 \\
.540\end{array}$ & $\begin{array}{l}-.182 \\
.024^{*}\end{array}$ & $\begin{array}{l}.117 \\
.150\end{array}$ & $\begin{array}{l}.126 \\
.119\end{array}$ \\
\hline $\begin{array}{l}\text { FLtotal } \\
p \text {-value }\end{array}$ & & & 1 & $\begin{array}{l}.336 \\
<.001 * *\end{array}$ & $\begin{array}{l}.342 \\
<.001 * *\end{array}$ & $\begin{array}{l}.351 \\
<.001 * *\end{array}$ & $\begin{array}{l}.104 \\
.204\end{array}$ & $\begin{array}{l}-.131 \\
.106\end{array}$ & $\begin{array}{l}.008 \\
.923\end{array}$ & $\begin{array}{l}-.181 \\
.025 *\end{array}$ & $\begin{array}{l}.100 \\
.219\end{array}$ & $\begin{array}{l}.175 \\
.030 *\end{array}$ \\
\hline $\begin{array}{l}\text { Cohes } \\
\text { p-value }\end{array}$ & & & & 1 & $\begin{array}{l}.708 \\
<.001 * *\end{array}$ & $\begin{array}{l}.914 \\
<.001 * *\end{array}$ & $\begin{array}{l}-.124 \\
.131\end{array}$ & $\begin{array}{l}-.143 \\
.076\end{array}$ & $\begin{array}{l}-.106 \\
.192\end{array}$ & $\begin{array}{l}-.064 \\
.430\end{array}$ & $\begin{array}{l}-.018 \\
.821\end{array}$ & $\begin{array}{l}.072 \\
.374\end{array}$ \\
\hline $\begin{array}{l}\text { Adapt } \\
\text { p-value }\end{array}$ & & & & & 1 & $\begin{array}{l}.889 \\
<.001^{* *}\end{array}$ & $\begin{array}{l}.031 \\
.711\end{array}$ & $\begin{array}{l}-.147 \\
.069\end{array}$ & $\begin{array}{l}.011 \\
.890\end{array}$ & $\begin{array}{l}-.166 \\
.040 *\end{array}$ & $\begin{array}{l}.145 \\
.073\end{array}$ & $\begin{array}{l}.121 \\
.136\end{array}$ \\
\hline $\begin{array}{l}\text { Famfunc } \\
p \text {-value }\end{array}$ & & & & & & 1 & $\begin{array}{l}-.077 \\
.351\end{array}$ & $\begin{array}{l}-.142 \\
.080\end{array}$ & $\begin{array}{l}-.079 \\
.330\end{array}$ & $\begin{array}{l}-.104 \\
.200\end{array}$ & $\begin{array}{l}.048 \\
.556\end{array}$ & $\begin{array}{l}.105 \\
.196\end{array}$ \\
\hline
\end{tabular}


Table 3 (continued)

\begin{tabular}{|c|c|c|c|c|c|c|c|c|c|c|c|c|}
\hline & Core & Balance & FLtotal & Cohes & Adapt & Famfunc & $\begin{array}{l}\text { Parent } \\
\text { age }\end{array}$ & Support & distime & P. Eth & $\begin{array}{l}\text { Youth } \\
\text { Age }\end{array}$ & $\begin{array}{l}\text { Family } \\
\text { size }\end{array}$ \\
\hline $\begin{array}{l}\text { Parent age } \\
\text { p-value }\end{array}$ & & & & & & & 1 & $\begin{array}{l}-.244 \\
.003^{* *}\end{array}$ & $\begin{array}{l}.381 \\
.000^{* *}\end{array}$ & $\begin{array}{l}.081 \\
.324\end{array}$ & $\begin{array}{l}.678 \\
.000^{* *}\end{array}$ & $\begin{array}{l}.018 \\
.830\end{array}$ \\
\hline $\begin{array}{l}\text { Support } \\
\text { p-value }\end{array}$ & & & & & & & & 1 & $\begin{array}{l}-.044 \\
.592\end{array}$ & $\begin{array}{l}-.155 \\
.055\end{array}$ & $\begin{array}{l}-.180 \\
.025 *\end{array}$ & $\begin{array}{l}.225 \\
.005^{* *}\end{array}$ \\
\hline $\begin{array}{l}\text { Distime } \\
p \text {-value }\end{array}$ & & & & & & & & & 1 & $\begin{array}{l}.055 \\
.494\end{array}$ & $\begin{array}{l}.548 \\
.000^{* *}\end{array}$ & $\begin{array}{l}.029 \\
.721\end{array}$ \\
\hline $\begin{array}{l}\text { P. Eth } \\
p \text {-value }\end{array}$ & & & & & & & & & & 1 & $\begin{array}{l}-.075 \\
.358\end{array}$ & $\begin{array}{l}-.202 \\
.012 *\end{array}$ \\
\hline $\begin{array}{l}\text { Youth age } \\
\text { p-value }\end{array}$ & & & & & & & & & & & 1 & $\begin{array}{l}.225 \\
.005^{* *}\end{array}$ \\
\hline $\begin{array}{l}\text { Familysize } \\
\text { p-value }\end{array}$ & & & & & & & & & & & & 1 \\
\hline
\end{tabular}

Note . Core = core family leisure patterns; Balance = balance family leisure patterns; FLtotal = total family leisure involvement; Cohes =

family cohesion; Adapt = family adaptability; Famfunc = family functioning; Support = level of support needed by child with

developmental disability; Distime $=$ length of time child with disability has been in family; P. Eth $=$ ethnic majority of parents. $*=p<.05$;

$* *=p<.01$. 
Table 4

Zero Order Pearson Correlations: Youth Data

\begin{tabular}{|c|c|c|c|c|c|c|c|c|c|c|c|}
\hline & Core & Balance & FLtotal & Cohes & Adapt & Famfunc & Support & $\begin{array}{l}\text { Youth } \\
\text { Age }\end{array}$ & Distime & Income & $\begin{array}{l}\text { Divorce } \\
\text { history }\end{array}$ \\
\hline $\begin{array}{l}\text { Core } \\
\text { p-value }\end{array}$ & 1 & $\begin{array}{l}.537 \\
<.001^{* *}\end{array}$ & $\begin{array}{l}.843 \\
<.001^{* *}\end{array}$ & $\begin{array}{l}.349 \\
.006^{* *}\end{array}$ & $\begin{array}{l}.420 \\
.001^{* *}\end{array}$ & $\begin{array}{l}.408 \\
.001^{* *}\end{array}$ & $\begin{array}{l}-.036 \\
.783\end{array}$ & $\begin{array}{l}-.076 \\
.560\end{array}$ & $\begin{array}{l}-.048 \\
.714\end{array}$ & $\begin{array}{l}.017 \\
.899\end{array}$ & $\begin{array}{l}.099 \\
.447\end{array}$ \\
\hline $\begin{array}{l}\text { Balance } \\
p \text {-value }\end{array}$ & & 1 & $\begin{array}{l}.906 \\
<.001^{* *}\end{array}$ & $\begin{array}{l}.044 \\
.738\end{array}$ & $\begin{array}{l}.105 \\
.424\end{array}$ & $\begin{array}{l}.108 \\
.413\end{array}$ & $\begin{array}{l}-.034 \\
.799\end{array}$ & $\begin{array}{l}-.017 \\
.900\end{array}$ & $\begin{array}{l}.084 \\
.523\end{array}$ & $\begin{array}{l}.134 \\
.308\end{array}$ & $\begin{array}{l}.051 \\
.701\end{array}$ \\
\hline $\begin{array}{l}\text { FLtotal } \\
p \text {-value }\end{array}$ & & & 1 & $\begin{array}{l}.183 \\
.166\end{array}$ & $\begin{array}{l}.262 \\
.045^{*}\end{array}$ & $\begin{array}{l}.256 \\
.050\end{array}$ & $\begin{array}{l}-.061 \\
.648\end{array}$ & $\begin{array}{l}-.040 \\
.766\end{array}$ & $\begin{array}{l}.054 \\
.684\end{array}$ & $\begin{array}{l}.085 \\
.523\end{array}$ & $\begin{array}{l}.060 \\
.651\end{array}$ \\
\hline $\begin{array}{l}\text { Cohes } \\
\text { p-value }\end{array}$ & & & & 1 & $\begin{array}{l}.643 \\
<.001 * *\end{array}$ & $\begin{array}{l}.906 \\
<.001^{* *}\end{array}$ & $\begin{array}{l}-.050 \\
.700\end{array}$ & $\begin{array}{l}-.216 \\
.092\end{array}$ & $\begin{array}{l}-.252 \\
.048 *\end{array}$ & $\begin{array}{l}. .161 \\
.210\end{array}$ & $\begin{array}{l}.212 \\
.098\end{array}$ \\
\hline $\begin{array}{l}\text { Adapt } \\
p \text {-value }\end{array}$ & & & & & 1 & $\begin{array}{l}.862 \\
<.001^{* *}\end{array}$ & $\begin{array}{l}.188 \\
.142\end{array}$ & $\begin{array}{l}-.015 \\
.908\end{array}$ & $\begin{array}{l}-.052 \\
.686\end{array}$ & $\begin{array}{l}-.094 \\
.467\end{array}$ & $\begin{array}{l}.138 \\
.284\end{array}$ \\
\hline $\begin{array}{l}\text { Famfunc } \\
p \text {-value }\end{array}$ & & & & & & 1 & $\begin{array}{l}-.004 \\
.978\end{array}$ & $\begin{array}{l}-.115 \\
.373\end{array}$ & $\begin{array}{l}-.205 \\
.110\end{array}$ & $\begin{array}{l}.168 \\
.193\end{array}$ & $\begin{array}{l}.144 \\
.264\end{array}$ \\
\hline
\end{tabular}


Table 4 (continued)

\begin{tabular}{|c|c|c|c|c|c|c|c|c|c|c|c|}
\hline & Core & Balance & FLtotal & Cohes & Adapt & Famfunc & Support & $\begin{array}{l}\text { Youth } \\
\text { Age }\end{array}$ & Distime & Income & $\begin{array}{l}\text { Divorce } \\
\text { history }\end{array}$ \\
\hline $\begin{array}{l}\text { Support } \\
p \text {-value }\end{array}$ & & & & & & & 1 & $\begin{array}{l}-.137 \\
.287\end{array}$ & $\begin{array}{l}-.044 \\
.595\end{array}$ & $\begin{array}{l}.169 \\
.036 *\end{array}$ & $\begin{array}{l}-.024 \\
.767\end{array}$ \\
\hline $\begin{array}{l}\text { Youth age } \\
\text { p-value }\end{array}$ & & & & & & & & 1 & $\begin{array}{l}-.044 \\
.592\end{array}$ & $\begin{array}{l}.222 \\
.083\end{array}$ & $\begin{array}{l}-.061 \\
.635\end{array}$ \\
\hline $\begin{array}{l}\text { Distime } \\
p \text {-value }\end{array}$ & & & & & & & & & 1 & $\begin{array}{l}.105 \\
.196\end{array}$ & $\begin{array}{l}-.064 \\
.433\end{array}$ \\
\hline $\begin{array}{l}\text { Income } \\
\text { p-value }\end{array}$ & & & & & & & & & & 1 & $\begin{array}{l}.255 \\
.001^{* *}\end{array}$ \\
\hline $\begin{array}{l}\begin{array}{l}\text { Divorce } \\
\text { history }\end{array} \\
\text { p-value }\end{array}$ & & & & & & & & & & & 1 \\
\hline
\end{tabular}

Note . Core $=$ core family leisure patterns; Balance $=$ balance family leisure patterns; FLtotal $=$ total family leisure involvement; Cohes $=$ family cohesion; Adapt = family adaptability; Famfunc = family functioning; Support = level of support needed by child with developmental disability; Distime $=$ length of time child with disability has been in family. ${ }^{*}=p<.05 ; * *=p<.01$ 
Table 5

Zero Order Pearson Correlations: Family Data (Parent and Youth)

\begin{tabular}{|c|c|c|c|c|c|c|c|c|c|c|}
\hline & Core & Balance & FLtotal & Cohes & Adapt & Famfunc & Support & $\begin{array}{l}\text { Ever } \\
\text { divorced }\end{array}$ & Income & $\begin{array}{l}\text { Youth } \\
\text { age }\end{array}$ \\
\hline $\begin{array}{l}\text { Core } \\
p \text {-value }\end{array}$ & 1 & $\begin{array}{l}.561 \\
<.001 * *\end{array}$ & $\begin{array}{l}.841 \\
<.001 * *\end{array}$ & $\begin{array}{l}.467 \\
<.001^{* *}\end{array}$ & $\begin{array}{l}.422 \\
.001^{* *}\end{array}$ & $\begin{array}{l}.478 \\
<.001 * *\end{array}$ & $\begin{array}{l}-.094 \\
.469\end{array}$ & $\begin{array}{l}.044 \\
.735\end{array}$ & $\begin{array}{l}.004 \\
.974\end{array}$ & $\begin{array}{l}-.054 \\
.677\end{array}$ \\
\hline $\begin{array}{l}\text { Balance } \\
\text { p-value }\end{array}$ & & 1 & $\begin{array}{l}.920 \\
<.001^{* *}\end{array}$ & $\begin{array}{l}.096 \\
.467\end{array}$ & $\begin{array}{l}.045 \\
.731\end{array}$ & $\begin{array}{l}.091 \\
.491\end{array}$ & $\begin{array}{l}-.059 \\
.652\end{array}$ & $\begin{array}{l}.051 \\
.700\end{array}$ & $\begin{array}{l}.155 \\
.238\end{array}$ & $\begin{array}{l}.012 \\
.926\end{array}$ \\
\hline $\begin{array}{l}\text { FLtotal } \\
p \text {-value }\end{array}$ & & & 1 & $\begin{array}{l}.279 \\
.032 *\end{array}$ & $\begin{array}{l}.207 \\
.115\end{array}$ & $\begin{array}{l}.278 \\
.033^{*}\end{array}$ & $\begin{array}{l}-.105 \\
.429\end{array}$ & $\begin{array}{l}.029 \\
.828\end{array}$ & $\begin{array}{l}.089 \\
.504\end{array}$ & $\begin{array}{l}-.017 \\
.897\end{array}$ \\
\hline $\begin{array}{l}\text { Cohes } \\
\text { p-value }\end{array}$ & & & & 1 & $\begin{array}{l}.649 \\
<.001^{* *}\end{array}$ & $\begin{array}{l}.928 \\
.000^{* *}\end{array}$ & $\begin{array}{l}-.206 \\
.108\end{array}$ & $\begin{array}{l}.135 \\
.297\end{array}$ & $\begin{array}{l}-.139 \\
.281\end{array}$ & $\begin{array}{l}-.201 \\
.117\end{array}$ \\
\hline $\begin{array}{l}\text { Adapt } \\
\text { p-value }\end{array}$ & & & & & 1 & $\begin{array}{l}.858 \\
<.001 * *\end{array}$ & $\begin{array}{l}.047 \\
.717\end{array}$ & $\begin{array}{l}.107 \\
.407\end{array}$ & $\begin{array}{l}-.012 \\
.927\end{array}$ & $\begin{array}{l}.007 \\
.958\end{array}$ \\
\hline
\end{tabular}


Table 5 (continued)

\begin{tabular}{|c|c|c|c|c|c|c|c|c|c|c|}
\hline & Core & Balance & FLtotal & Cohes & Adapt & Famfunc & Support & $\begin{array}{l}\text { Ever } \\
\text { divorced }\end{array}$ & Income & $\begin{array}{l}\text { Youth } \\
\text { age }\end{array}$ \\
\hline $\begin{array}{l}\text { Famfunc } \\
\text { p-value }\end{array}$ & & & & & & 1 & $\begin{array}{l}-.145 \\
.259\end{array}$ & $\begin{array}{l}.062 \\
.630\end{array}$ & $\begin{array}{l}-.108 \\
.402\end{array}$ & $\begin{array}{l}-.124 \\
.336\end{array}$ \\
\hline $\begin{array}{l}\text { Support } \\
\text { p-value }\end{array}$ & & & & & & & 1 & $\begin{array}{l}-.024 \\
.767\end{array}$ & $\begin{array}{l}-.169 \\
.036 *\end{array}$ & $\begin{array}{l}-.137 \\
.287\end{array}$ \\
\hline $\begin{array}{l}\begin{array}{l}\text { Ever } \\
\text { divorced }\end{array} \\
\text { p-value }\end{array}$ & & & & & & & & 1 & $\begin{array}{l}.255 \\
.001^{* *}\end{array}$ & $\begin{array}{l}-.061 \\
.635\end{array}$ \\
\hline $\begin{array}{l}\text { Income } \\
p \text {-value }\end{array}$ & & & & & & & & & 1 & $\begin{array}{l}.222 \\
.083\end{array}$ \\
\hline $\begin{array}{l}\text { Youth age } \\
\text {-value }\end{array}$ & & & & & & & & & & 1 \\
\hline
\end{tabular}

Note. Core = core family leisure patterns; Balance $=$ balance family leisure patterns; FLtotal = total family leisure involvement; Cohes =

family cohesion; Adapt = family adaptability; Famfunc = family functioning; Support = level of support needed by child with

developmental disability. $*=p<.05 ; * *=p<.01$ 
62 Family Leisure and Functioning

Table 6

Summary of Blocked Regression Equations Predicting Family Cohesion: Parent Data

\begin{tabular}{lllll}
\hline Predictor & $\boldsymbol{B}$ & $\boldsymbol{S E} \boldsymbol{B}$ & $\boldsymbol{\beta}$ & $\boldsymbol{p}$ \\
\hline & & & & \\
Block $1 \mathrm{R}^{2}=.066(p=.042)^{*}$ & & & & \\
& & & & \\
Parent age & -.195 & .110 & -.160 & .078 \\
Level of support needed by child & -2.690 & 1.082 & -.210 & $.014^{*}$ \\
Time child with disability in the home & -.795 & 1.060 & -.065 & .455 \\
Parent ethnicity majority & -2.922 & 2.055 & -.117 & .157 \\
& & & & \\
Block 2 $\Delta \mathrm{R}^{2}=.156(p<.001) * *$ & & & \\
& & & & \\
Parent age & & & & \\
Level of support needed by child & -.198 & .102 & -.162 & .054 \\
Time child with disability in the home & -1.993 & 1.006 & -.156 & .050 \\
Parent ethnicity majority & -.479 & .977 & -.039 & .625 \\
Core family leisure & -1.250 & 1.931 & -.050 & .518 \\
Balance family leisure & .239 & .057 & .379 & $<.001 * *$ \\
& .016 & .037 & .040 & .660 \\
& & & & \\
\hline
\end{tabular}

Note. ${ }^{*} p<.05 ; * * p<.01 ; n=149$. A Bonferroni adjustment was used for multiple tests.

A family-wise .05 significance level was used overall, but the Bonferroni adjustment of

.01 (or less) significance level was used for individual tests. 
Family Leisure and Functioning 63

Table 7

Summary of Blocked Regression Equations Predicting Family Adaptability: Parent Data

Predictor

$B$

$S E B$

$\boldsymbol{\beta} \quad \boldsymbol{p}$

Block $1 \mathrm{R}^{2}=.079(p=.015)^{*}$

Level of support needed by child

$-1.674$

.762

$-.184 \quad .030^{*}$

Parent ethnicity majority

Age of child with disability

$-2.983$

1.452

.081

.090

$-.166 .042 *$

Family size

.475

.361

$.074 \quad .374$

$.112 \quad .191$

Block $2 \Delta \mathrm{R}^{2}=.116(p<.001)^{* *}$

Level of support needed by child

Parent ethnicity majority

Age of child with disability

Family size

$-1.099$

$-2.283$

.731

$\begin{array}{ll}-.121 \quad .135 \\ -.127 & .102\end{array}$

.100

1.389

$\begin{array}{ll}-.127 \quad .102 \\ -.092 & .245\end{array}$

.125

.085

$.092 \quad .245$

Core family leisure

.161

.348

$.030 \quad .719$

Balance family leisure

$-.003$

.041

$.630<.001^{* *}$

.026

$-.009 \quad .919$

Note. ${ }^{*} p<.05 ; * * p<.01 ; n=153$. A Bonferroni adjustment was used for multiple tests.

A family-wise .05 significance level was used overall, but the Bonferroni adjustment of .01 (or less) significance level was used for individual tests. 
64 Family Leisure and Functioning

Table 8

Summary of Blocked Regression Equations Predicting Family Functioning: Parent Data

\begin{tabular}{lllll}
\hline Predictor & $\boldsymbol{B}$ & $\boldsymbol{S} \boldsymbol{E} \boldsymbol{B}$ & $\boldsymbol{\beta}$ & $\boldsymbol{p}$ \\
\hline & & & & \\
Block $1 \mathrm{R}^{2}=.032(p=.090)$ & & & & \\
& & & & \\
Parent age & -.023 & .016 & -.117 & .163 \\
Level of support needed by child & -.341 & .170 & -.167 & $.047^{*}$ \\
& & & & \\
Block 2 $\Delta \mathrm{R}^{2}=.176(p<.001) * *$ & & & & \\
Parent age & & & & \\
Level of support needed by child & -.024 & .015 & -.121 & .118 \\
Core family leisure & -.249 & .156 & -.122 & .114 \\
Balance family leisure & .038 & .009 & .380 & $<.001^{* *}$ \\
& -.004 & .006 & -.069 & .445 \\
\hline
\end{tabular}

Note. ${ }^{*} p<.05 ; * * p<.01 ; n=149$. A Bonferroni adjustment was used for multiple tests.

A family-wise .05 significance level was used overall, but the Bonferroni adjustment of .01 (or less) significance level was used for individual tests. 
Family Leisure and Functioning 65

Table 9

Summary of Blocked Regression Equations Predicting Family Cohesion: Youth Data

\begin{tabular}{|c|c|c|c|c|}
\hline Predictor & $\boldsymbol{B}$ & $S E B$ & $\beta$ & $p$ \\
\hline \multicolumn{5}{|l|}{ Block $1 \mathrm{R}^{2}=.013(p .396)$} \\
\hline Level of support needed by child & -1.568 & 1.832 & -.113 & .396 \\
\hline \multicolumn{5}{|l|}{ Block $2 \Delta \mathrm{R}^{2}=.114(p=.034)^{*}$} \\
\hline Level of support needed by child & -1.274 & 1.759 & -.092 & .472 \\
\hline Core family leisure & .189 & .071 & .399 & $.010^{*}$ \\
\hline Balance family leisure & -.065 & .056 & -.176 & .244 \\
\hline
\end{tabular}

Note. ${ }^{*} p<.05 ; * * p<.01 ; n=58$. A Bonferroni adjustment was used for multiple tests.

A family-wise .05 significance level was used overall, but the Bonferroni adjustment of .01 (or less) significance level was used for individual tests. 
66 Family Leisure and Functioning

Table 10

Summary of Blocked Regression Equations Predicting Family Adaptability: Youth Data

\begin{tabular}{lllll}
\hline Predictor & & & & \\
& & $S \boldsymbol{B}$ & $\boldsymbol{\beta}$ & $\boldsymbol{p}$ \\
\hline Block $1 \mathrm{R}^{2}=.062(p=.623)$ & & & & \\
& & & & \\
Level of support needed by child & 1.281 & 1.581 & .110 & .421 \\
Youth age & .183 & .502 & .051 & .717 \\
Time child with disability in the home & .805 & 1.692 & .066 & .636 \\
Income & -.823 & .494 & -.242 & .102 \\
Divorced history & 1.890 & 2.546 & .104 & .461 \\
& & & & \\
Block 2 $\Delta \mathrm{R}^{2}=.168(p=.006) * *$ & & & \\
& & & & \\
Level of support needed by child & 1.670 & 1.465 & .143 & .260 \\
Youth age & .259 & .464 & .072 & .580 \\
Time child with disability in the home & .930 & 1.567 & .076 & .555 \\
Income & .764 & .461 & -.225 & .104 \\
Divorce history & 1.402 & 2.356 & .077 & .554 \\
Core family leisure & .185 & .058 & .465 & $.003 * *$ \\
Balance family leisure & -.038 & .046 & -.120 & .419 \\
& & & & \\
\hline
\end{tabular}

Note. ${ }^{*} p<.05 ;{ }^{* *} p<.01 ; n=58$. A Bonferroni adjustment was used for multiple tests. A familywise .05 significance level was used overall, but the Bonferroni adjustment of .01 (or less) significance level was used for individual tests. 
Family Leisure and Functioning 67

Table 11

Summary of Blocked Regression Equations Predicting Family Functioning: Youth Data

\begin{tabular}{lllll}
\hline Predictor & $\boldsymbol{B}$ & $\boldsymbol{S E} \boldsymbol{B}$ & $\boldsymbol{\beta}$ & $\boldsymbol{p}$ \\
\hline & & & & \\
Block $1 \mathrm{R}^{2}=.100(p=.330)$ & & & & \\
& & & & \\
Level of support needed by child & -.259 & .303 & -.113 & .396 \\
Youth age & -.028 & .096 & -.039 & .776 \\
Time child with disability in the home & -.302 & .324 & -.126 & .356 \\
Income & -.162 & .095 & -.244 & .093 \\
Divorce history & .512 & .487 & .144 & .298 \\
& & & & \\
Block 2 $\Delta \mathrm{R}^{2}=.134(p=.016)$ & & & & \\
& & & & \\
Level of support needed by child & -.191 & .285 & -.084 & .507 \\
Youth age & -.014 & .090 & -.019 & .882 \\
Time child with disability in the home & -.284 & .305 & -.119 & .357 \\
Income & -.154 & .090 & -.231 & .093 \\
Divorce history & .428 & .459 & .120 & .355 \\
Core family leisure & .032 & .011 & .406 & $.008^{* *}$ \\
Balance family leisure & -.005 & .009 & -.081 & .583 \\
& & & & \\
\hline
\end{tabular}

Note. ${ }^{*} p<.05 ; * * p<.01 ; n=58$. A Bonferroni adjustment was used for multiple tests. A familywise .05 significance level was used overall, but the Bonferroni adjustment of .01 (or less) significance level was used for individual tests. 
68 Family Leisure and Functioning

Table 12

Summary of Blocked Regression Equations Predicting Family Cohesion: Family Data (Parent and Youth)

\begin{tabular}{lllll}
\hline Predictor & $\boldsymbol{B}$ & $\boldsymbol{S} \boldsymbol{E} \boldsymbol{B}$ & $\boldsymbol{\beta}$ & $\boldsymbol{p}$ \\
\hline & & & & \\
Block $1 \mathrm{R}^{2}=.137(p=.088)$ & & & & \\
& & & & \\
Level of support needed by child & -3.250 & 1.597 & -.260 & $.047^{*}$ \\
Divorce history & 2.919 & 2.590 & .150 & .265 \\
Income & -.598 & .495 & -.164 & .232 \\
Youth age & -.713 & .508 & -.185 & .166 \\
& & & & \\
Block 2 $\Delta \mathrm{R}^{2}=.202(p=.001)^{* *}$ & & & & \\
Level of support needed by child & & & & \\
Divorce history & -2.656 & 1.435 & -.212 & .070 \\
Income & 2.799 & 2.310 & .143 & .231 \\
Youth age & -.485 & .448 & -.133 & .284 \\
Core family leisure & -.617 & .454 & -.160 & .180 \\
Balance family leisure & .291 & .075 & .536 & $<.001^{* *}$ \\
& -.081 & .055 & -.206 & .143 \\
& & & & \\
\hline
\end{tabular}

Note. ${ }^{*} p<.05 ; * * p<.01 ; n=58$. A Bonferroni adjustment was used for multiple tests. A family-wise .05 significance level was used overall, but the Bonferroni adjustment of .01 (or less) significance level was used for individual tests. 
Family Leisure and Functioning 69

Table 13

Summary of Blocked Regression Equations Predicting Family Adaptability: Family Data (Parent and Youth)

\begin{tabular}{lllll}
\hline Predictor & $\boldsymbol{B}$ & $\boldsymbol{S E} \boldsymbol{B}$ & $\boldsymbol{\beta}$ & $\boldsymbol{p}$ \\
\hline & & & & \\
Block $1 \mathrm{R}^{2}=.013(p=.945)$ & & & & \\
& & & & \\
Level of support needed by child & -.291 & 1.236 & -.032 & .815 \\
Divorce history & .881 & 2.003 & .062 & .662 \\
Income & -.305 & .383 & -.116 & .429 \\
Youth age & .030 & .393 & .011 & .940 \\
& & & & \\
Block 2 $\Delta \mathrm{R}^{2}=.226(p=.001) * *$ & & & & \\
& & & & \\
Level of support needed by child & .121 & 1.113 & .013 & .914 \\
Divorce history & .779 & 1.793 & .055 & .666 \\
Income & -.188 & .347 & -.071 & .591 \\
Youth age & .098 & .352 & .035 & .782 \\
Core family leisure & .228 & .058 & .579 & $<.001 * *$ \\
Balance family leisure & -.085 & .042 & -.297 & .050 \\
& & & & \\
\hline
\end{tabular}

Note. ${ }^{*} p<.05 ;{ }^{*} p<.01 ; n=58$. A Bonferroni adjustment was used for multiple tests. A family-wise .05 significance level was used overall, but the Bonferroni adjustment of .01 (or less) significance level was used for individual tests. 
70 Family Leisure and Functioning

Table 14

Summary of Blocked Regression Equations Predicting Family Functioning: Family Data (Parent and Youth)

\begin{tabular}{lllll}
\hline Predictor & $\boldsymbol{B}$ & $\boldsymbol{S} \boldsymbol{E} \boldsymbol{B}$ & $\boldsymbol{\beta}$ & $\boldsymbol{p}$ \\
\hline & & & & \\
Block $1 \mathrm{R}^{2}=.074(p=.374)$ & & & & \\
& & & & \\
Level of support needed by child & -.423 & .273 & -.205 & .127 \\
Divorce history & .191 & .443 & .059 & .668 \\
Income & -.084 & .085 & -.139 & .327 \\
Youth age & -.079 & .087 & -.124 & .370 \\
Block $2 \Delta \mathrm{R}^{2}=.237(p<.001) * *$ & & & \\
& & & & \\
Level of support needed by child & & & -.154 & .193 \\
Divorce history & -.319 & .242 & .052 & .667 \\
Income & .169 & .389 & -.103 & .418 \\
Youth age & -.062 & .075 & -.097 & .424 \\
Core family leisure & -.062 & .076 & .585 & $<.001 * *$ \\
Balance family leisure & .053 & .013 & -.245 & .089 \\
& -.016 & .009 & & \\
\hline
\end{tabular}

Note. ${ }^{*} p<.05 ; * * p<.01 ; n=58$. A Bonferroni adjustment was used for multiple tests. A family-wise .05 significance level was used overall, but the Bonferroni adjustment of .01 (or less) significance level was used for individual tests. 
Family Leisure and Functioning 71

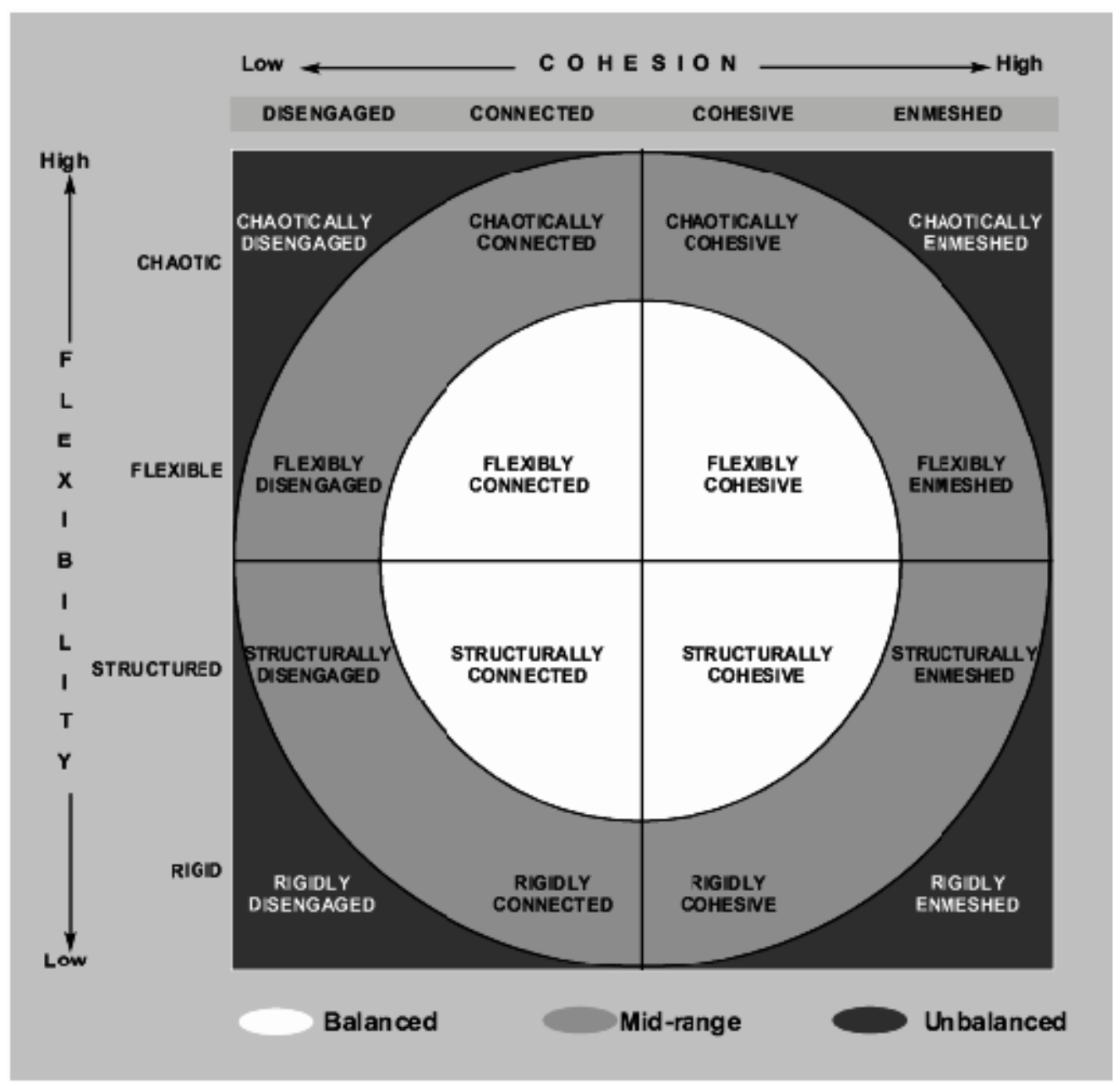

Figure 1. Olsen's Family Circumplex Model 
72 Family Leisure and Functioning

\section{Core \& Balance Model of Family Leisure Functioning}



Figure 2. Core and Balance Model of Family Leisure Functioning 
Appendix A

Prospectus 


\section{Chapter 1}

\section{Introduction}

Researchers consistently find positive relationships between family leisure involvement and family functioning (Freeman \& Zabriskie, 2003; Orthner \& Mancini, 1991; Zabriskie, 2000, 2001; Zabriskie \& Freeman, 2004; Zabriskie \& McCormick, 2001, 2003). Although many studies examine leisure among traditional families, very little research focuses on families that vary from the traditional structure. Among others, scholars (Mactavish \& Schleien, 1997, 1998, 2004) call for a greater understanding of family leisure among families who have children with developmental disabilities.

Families that include children with developmental disabilities face a unique set of challenges and stressors. Singer (2002) explained that children with developmental disabilities often require high levels of supervision, extensive long-term medical care, and have serious challenging behaviors. They may also require more physical and emotional aid from their parents than children without disabilities. Many researchers (Glidden, 1993; Mactavish \& Schleien, 1997; Olsson \& Hwang, 2001; Summers et al., 2005; Warfield, Krauss, Hauser-Cram, Upshur, \& Shonkoff, 1999) agree that families who have children with developmental disabilities face substantially greater challenges and have higher levels of stress when compared to families whose children do not have disabilities. These challenges and stressors impose more constraints on the families (Scholl, McAvoy, Rynders, \& Smith, 2003; Singer, 2002). Baker, Blacher, Crnic, and Edelbrock (2002) found the impact of stress seemed to vary according to the characteristics of the child. For example, parents of children with problem behaviors 
(emotional reactivity depressed / anxious, withdrawn, somatic, sleep problems, attention, and aggression,) reported higher levels of stress.

Because these families have added stress and challenges, researchers tend to “make blanket attributions characterizing families as maladaptive and marked by pathology” (Singer, 2002, p. 150). Glidden (1993) explained that uncritical acceptance of this view is dangerous because "adjustment or maladjustment is dependent not only on the presence or absence of stress, but also on the presence or absence of positive outcomes. Positive outcomes can coexist and even be orthogonal to negative outcomes” (p. 482). Because researchers were not hypothesizing positive outcomes to having children with disabilities in a family, they were not finding any (Glidden, 1993). Researchers (Blacher, 2001; Ferguson, 2002; Kwai-sang \& Li-Tsang, 1999; Singer, 2002; Taunt \& Haustings, 2002) recently identified a number of benefits associated with having a child with a disability in a family. Some of these benefits include personal growth, a sense of meaningfulness in life, and strengthening of marriages (Kwai-sang \& Li-Tsang, 1999). Many families of children with developmental disabilities cope effectively and adjust positively to the added demands of raising a child with a disability (Blacher, 2001; Ferguson, 2002; Taunt \& Hastings, 2002).

Contrary to early research (Kronick, 1976; Margalit \& Heiman, 1986), family functioning in families who have children with disabilities is similar to traditional families with children who achieve at normal levels. Families with children who have disabilities have positive and cohesive family relationships, use rules for operating the family routine (Dyson, 1996), and function at or near normal levels based on families in 
general (Cahill \& Glidden, 1996). In fact, according to Ferguson (2002), an increasingly dominant body of research shows families with and without children with disabilities as having similar patterns of overall adjustment and well-being.

Research examining leisure in families with children who have disabilities is in its infancy (Mactavish \& Schleien, 1997, 2004; Mactavish, Schleien, \& Tabourne, 1997; Scholl et al., 2003). Studies report a variety of outcomes such as increased confidence in their family as a unit; increased awareness of family skill level and support needs; and find these families view family leisure as a means to promote family functioning and overall quality of family life (Mactavish \& Schleien, 1998; Scholl et al., 2003). According to Mactavish and Schleien (1998), family leisure involvement for such families appears to be most effective with the family as a whole, much more than for couples alone and "concentrating on adult-only perceptions may under estimate the positive value of shared recreation for the family as a whole” (p. 226).

While these studies provide a sound basis for this emerging line of research, they primarily utilize qualitative methodologies among relatively small samples of families that include a child with a disability. The next logical step is to examine the contributions of family leisure involvement to measurable outcomes such as aspects of family functioning in a larger sample of families who have a child with a disability. Recent studies among other types of families (Freeman \& Zabriskie, 2003; Zabriskie \& Freeman, 2004; Zabriskie \& McCormick, 2001, 2003) have followed Mactavish and Schleien’s (1998) recommendation and used a family systems perspective as a theoretical framework from which to examine the contributions of family leisure. 
Family systems theory describes the family as a system that works together. Each action from the separate parts or individual family members affects the others. In order to create a healthy, successfully functioning family system each member of the family must be involved. No separate part or individual family member can act on its own without affecting the other members of the family. Healthy families are goal oriented, dynamic, self-correcting, and are affected by and affect their environment (Klein and White, 1996). Olson’s (1993) Circumplex Model of Marital and Family Systems describes family functioning through varying levels of cohesion and adaptability. A healthy family displays a balance of moderate cohesion and adaptability across the lifespan. This means that the family is both connected and separate (cohesion) and can manage change as well as stability (adaptability) (Olson, 1993). Many aspects can affect family functioning, and recent research points toward family leisure as an important factor.

Zabriskie and McCormick (2001) classify family leisure into two main categories; Core family leisure patterns and Balance family leisure patterns. Core family leisure activities are common, everyday, low-cost, and frequent activities. They are usually home-based, spontaneous, and informal, requiring little planning or resources. Balance family leisure activities are usually less frequent and less common than core family leisure and take place away from the home. They require more resources such as time, effort, and money, and because they require substantial planning, they are usually less spontaneous, more formal, and longer in duration than core activities. These activities are more challenging and are not commonplace for the family. When families are involved in both core and balance family leisure, their family functioning is reported as more 
successful than families who participate in lower levels or extreme levels of core and balance family leisure. Family leisure involvement in both core and balance activities fulfill the need for stability and change within a family system (Zabriskie \& McCormick, 2001). The Core and Balance Model of Family Leisure Functioning suggests that families who are involved in less family leisure tend to have lower levels of family cohesion and adaptability than those who are involved in more.

Olson (2000) suggests that a family’s ability to successfully function as a system is demonstrated through its capacity to meet needs for cohesion (their emotional bonds or feelings of closeness) and adaptability (their ability to cope with change). Zabriskie and Freeman (2004) argue that such needs are often met through family leisure involvement. Core family leisure provides a safe, positive, and predictable context for family members to form cohesion and closeness while balance family leisure provides opportunities for novelty, change, challenge, and unpredictability and as a result helps family members to negotiate and adapt together (Zabriskie \& Freeman, 2004). Studies using the Core and Balance Framework (Zabriskie, 2000; Zabriskie \& McCormick, 2001, 2003) consistently support these relationships among traditional family samples. Known group studies also support the construct validity, or the Core and Balance Model, by correctly predicting family leisure relationships among samples of families with known characteristics such as those with special needs adoptive children (Zabriskie \& Freeman, 2004), youth in mental health treatment, Hispanic families (Christenson, Zabriskie, Eggett, \& Freeman, in press), or single parent families (Smith, Taylor, Hill, \& Zabriskie, 2004). Researchers (Freeman \& Zabriskie, 2003; Zabriskie, 2000, 2001; Zabriskie \& Freeman, 2004; 
Zabriskie \& McCormick, 2001, 2003) call for further known group studies of different family types including families with children with developmental disabilities.

\section{Statement of the Problem}

The problem of this study is to examine the relationship between family leisure involvement and family functioning among families that include children with developmental disabilities.

Purpose of the Study

Research examining recreation in families with children with disabilities is a fairly new line of research and as with most research in the beginning stages. Researchers (Mactavish \& Schleien, 1997, 2004; Mactavish et al., 1997; Scholl et al., 2003) have mainly used qualitative research methods with rather small sample sizes. Although this is a necessary beginning step, broader more representative samples are needed as well as additional studies using quantitative research methods. The purpose of this study is to acquire further understanding of the relationship between family leisure involvement and family functioning among families with children with developmental disabilities by using quantitative research methods with a broad, more representative sample. While furthering this line of study, such research may also provide insight and direction for researchers and practitioners attempting to strengthen families and improve family functioning of families that include children with developmental disabilities.

\section{Significance of the Study}

Families that include children with developmental disabilities often have higher levels of stress and pressure than families with children without disabilities (Mactavish \& 
Schleien, 1997; Olsson \& Hwang, 2001; Scholl et al., 2003; Warfield et al., 1999). They face medical care and expenses, supervision needs, and challenging behaviors (Dumas, Wolf, Fisman, \& Cullingan, 1991). They encounter more constraints due to economic, physical, and emotional demands (Scholl et al., 2003). Even with these added challenges and demands, recent researchers (Blacher, 2001; Ferguson, 2002; Taunt \& Hastings, 2002) find these families adjust positively and cope effectively with the added demands of raising a child with a developmental disability. Contrary to previous research, Cahill and Glidden (1996), Dyson (1996), and Ferguson (2002) found that families with children with developmental disabilities function at or near the same levels as traditional families without children with disabilities. They have positive and cohesive family relationships (Dyson, 1996).

Olson (1986) defines family cohesiveness and adaptability as "characteristics of highly functioning families" (p. 339). Family leisure plays a vital role in "family cohesion, adaptability, and communication” (Zabriskie \& McCormick, 2001, p. 282). Recent studies show a positive relationship between family leisure involvement and successful family functioning (Freeman \& Zabriskie, 2003; Zabriskie, 2000, 2001; Zabriskie \& Freeman, 2004; Zabriskie \& McCormick, 2001, 2003), and in families that include a child with a developmental disability, there is an intensified importance attributed to leisure (Mactavish \& Schleien, 1998).

Researchers have expressed the need for studies regarding non-traditional families (Holman \& Epperson, 1984; Zabriskie \& McCormick, 2003). Mactavish and Schleien (2004) declared that "recreation in families that include children with 
developmental disabilities is a neglected area of research in both disability studies and leisure studies” (p. 125). An effort to respond to this neglect may provide considerable insight into the possible relationship between family leisure and family functioning among families that include children with disabilities. "Although shared leisure activities are not a panacea for all family problems, family leisure affects the quality of life and may be particularly helpful in facilitating family cohesion and adaptability” (Zabriskie, 2001, p. 287), particularly among this population. If it can be determined that family leisure involvement is indeed correlated to positive family functioning among families that include children with developmental disabilities, then this information could be used to further strengthen and improve the functioning of these families. This research will also add to the growing body of knowledge that examines family leisure in families that include children with developmental disabilities.

\section{Delimitations}

The scope of the study will be delimited to the following:

1. This study will include a minimum of 100 families with at least one child per family with a developmental disability and another child per family who is 10 to 17 years.

2. Responses will be collected from one youth between the ages of 10 and 17 and one parent from each family.

3. Family leisure patterns will be measured with the Family Leisure Activity Profile (FLAP) (Zabriskie \& McCormick, 2001). 
4. Family functioning (cohesion and adaptability) will be measured with the Family Adaptability and Cohesion Evaluation Scales (FACES II) (Olson, 2000).

5. Data will be collected, beginning June 2006, until a sufficient pool is found (at least 100 families).

6. Data will not be collected from the child with the disability.

7. This study will use a convenience sample.

\section{Limitations}

This study will be limited by the following factors:

1. The influence of the parent on the child doing the questionnaire cannot be followed.

2. Each questionnaire will be self-reported which may be influenced by social desirability in some respondents.

3. Due to the fact that the methods of this study are correlational, causal relationships cannot be determined.

4. This study will not utilize a random sample, and therefore external validity will be somewhat limited.

Assumptions

This study will be conducted based upon the following assumptions:

1. Valid and reliable inferences can be made from FACES II regarding family functioning.

2. Valid and reliable inferences can be made from FLAP regarding family leisure involvement. 
3. Participants will be honest when completing the questionnaire. Hypotheses

This study was designed to test the following null hypotheses:

1. No relationship will be found between family leisure involvement and family functioning among families that include children with developmental disabilities after adjusting for the functioning level of the child with a disability.

2. No relationship will be found between core family leisure patterns and family cohesion after adjusting for the functioning level of the child with a disability.

3. No relationship will be found between balance family leisure patterns and family adaptability after adjusting for the functioning level of the child with a disability.

4. A difference in levels of family functioning and family leisure involvement between families with a child with a disability and a previously collected sample of families who do not have a child with a disability will be found.

Definitions of Terms

The following terms are defined to clarify their use in this study:

Balance leisure patterns. Leisure activities that are less frequent, less common, and require more resources (e.g., time, effort, and money) than core activities. Because they require substantial planning, they are usually less spontaneous, more formal, and longer in duration (Zabriskie \& McCormick, 2001).

Core leisure patterns. Leisure activities that are common, everyday, low-cost, and participated in frequently. These activities are usually home-based, require little planning and resources, and are spontaneous, and informal (Zabriskie \& McCormick, 2001). 
Developmental disability. “A severe and chronic disorder involving mental and / or physical impairment that originates before age 22. Such a disability is likely to persist indefinitely, and will cause substantial functional limitation in at least three of the following seven areas of major life activities: self-care, receptive and expressive language, learning, mobility, self-direction, capacity for independent living, economic self-sufficiency” (Mactavish et al., 1997, p. 26). Some examples of these disabilities include mental retardation, Down syndrome, cerebral palsy, autism, severe multiple disability, rubenstein-tabyi syndrome, aspergers, attention deficit hyperactivity disorder, fragile X syndrome, etc.)

Family. “A social group with whom one resides” (Landesman \& Vietz, 1987). A household including a mother, father, and/or guardian, one dependent between the ages of 10 and 17, and at least one child with a developmental disability.

Family adaptability. The family’s ability, in response to situational and developmental stress, to change its power structure, role relationships, and relationship rules (Olson, Portner, \& Bell, 1982).

Family cohesion. The emotional bonding between family members (Olson et al., 1982).

Family leisure patterns. Participation in activities together as a family as described in the Core and Balance Model of Family Leisure Functioning. The two main categories or patterns of leisure are Core and Balance leisure activities. 


\section{Chapter 2}

\section{Review of Literature}

The problem of the study is to examine the contribution of family leisure involvement to family functioning among families that include children with developmental disabilities. For organizational purposes, the literature will be presented under the following topics (a) families of children with developmental disabilities (b) family functioning in families of children with developmental disabilities, (c) family leisure in families of children with developmental disabilities, (d) family leisure, and (e) core and balance model of family leisure functioning.

\section{Families of Children with Developmental Disabilities}

Historically children with disabilities did not reside with their families, but instead were institutionalized. Therefore, they had little contact with their families. This began to change in the 1960s as the idea of normalization emerged. Normalization was an attempt to increase the rights of individuals with disabilities to give them culturally normal life conditions. As a result, children with disabilities began to live with their families or in family situations rather than institutions (Landesman \& Vietze, 1987). Since that time, children with developmental disabilities have lived in diverse family situations. While most of these children live in nuclear families with their biological parents and siblings, still many do not (Mactavish et al., 1997). Many of these children live in single parent homes, adoptive homes, foster homes that do not culminate into permanent adoptive homes (Landesman \& Vietz, 1987), or group homes. Of the children who are adopted, many have never previously experienced consistent, caring, or trusting human 
relationships, and as a result have developed dysfunctional coping behaviors and disruptive behaviors such as violence, inappropriate sexual activity, lying, or stealing (Lashua, Widmer, \& Munson, 2000). “Family” for children with developmental disabilities has come to mean, “a social group with whom one resides” (Landesman \& Vietz, 1987, p. 61). Researchers in many disciplines have focused on "maintaining children with disabilities in their family homes” (Mactavish et al., 1997, p. 23). For at least four decades, a popular focus of research in the disability studies has been families that include children with developmental disabilities (Singer, 2002).

Previously researchers tended to "make blanket attributions characterizing (such) families as maladaptive and marked by pathology” (Singer, 2002, p. 150). This was due, in large part, to a lack of comparison groups, samples that only represented families seeking services, use of instruments without rigorous psychometric development, lack of replication, and results from mothers generalized to the entire family (Glidden, 1993). Uncritical acceptance of this view is dangerous because "adjustment or maladjustment is dependent not only on the presence or absence of stress, but also on the presence or absence of positive outcomes. Positive outcomes can coexist and even be orthogonal to negative outcomes” (Glidden, 1993, p. 482). Because researchers were not looking for and hypothesizing positive outcomes associated with having a child with a disability in a family, they were not finding any (Glidden, 1993). Researchers (Blacher, 2001;

Ferguson, 2002; Kwai-sang \& Li-Tsang, 1999; Singer, 2002; Taunt \& Haustings, 2002) are beginning to examine and identify benefits of having a child with a disability in a family. Some of these benefits include “(a) Pleasure / satisfaction in providing care for 
the child, (b) The child as a source of joy / happiness, (c) The child provides a challenge or opportunity to learn and develop, (d) Strengthened family and / or marriage, (e) A new or increased sense of purpose in life, (f) Development of new skills, abilities, or new career opportunities, (g) Family members have experienced personal growth, (h) Expanded social and community networks, (i) Increased spirituality, and (j) A changed perspective on life” (Taunt \& Haustings, 2002, p. 411). It is only recently that studies show these families to cope effectively and adjust positively to the added demands of raising a child with a disability (Blacher, 2001; Ferguson, 2002; Taunt \& Hastings, 2002).

Although there may be benefits associated with raising a child with a developmental disability, there definitely are added demands and increased challenges. Many researchers (Glidden, 1993; Mactavish \& Schleien, 1997; Olsson \& Hwang, 2001; Summers et al., 2005; Warfield et al., 1999) agree that families with children with developmental disabilities face greater challenges and have higher levels of stress when compared to families whose children do not have disabilities. The impact of this greater stress appears to vary according to the characteristics of the child. Parents of children with problem behaviors report higher levels of stress than other parents (Baker et al., 2002). Challenges and stress faced by families of children with disabilities result in more constraints to the families (Scholl et al., 2003; Singer, 2002). For example, these children often require high levels of supervision, extensive long-term medical care, and have serious challenging behaviors. They also may require more physical and emotional demands from their parents than children without disabilities (Singer, 2002). Each family 
is unique in its level of resiliency and ability to adapt to the added demands and stress of having a child with a disability. The level of disability, and family structure (family size, single parents) may not be as critical to the ability of a family to adapt as is the presence or absence of self-injurious or challenging behaviors and family income (Ferguson, 2002). The presence of stress and demands does not necessarily predict maladjustment and low functioning in a family; instead, their ability to adjust and cope with the demands determines the family's level of functioning.

Parents and siblings are extremely influential in the success of children with developmental disabilities. Positive self-identity, self-determination, stigmatization, and other directedness begin early in life (Powers \& Singer, 1996). Fifteen successful adults with disabilities expressed that they did not become aware of their devalued and unequal status until middle childhood; they were astonished when they found people outside their family viewed them as different. Their families were vital in development of a positive self-image because they allowed them to take risks and encouraged them to be assertive. Families with children with developmental disabilities often have higher levels of stress and demands, but most of them adapt and deal with these constraints and demands just like any traditional family would (Singer, 2002).

Family Functioning in Families of Children with Developmental Disabilities

Stability and change are two opposing needs or forces that influence individual behavior, (Iso-Ahola, 1984) and family systems (Klein \& White, 1996). A family system must meet the "need for stability in interactions, structure, and relationships, as well as a need for novelty in experience, input, and challenge” (Zabriskie \& McCormick, 2001, p. 
283) in order to function effectively. The Circumplex Model (Olson, 1986) suggests that two main constructs (family cohesion and family adaptability) indicate the family functioning level, and communication helps to facilitate these constructs. Family cohesion refers to feelings of personal relatedness and family closeness, while family adaptability refers to the family’s ability to develop, adapt, and function as a working unit. Klein and White (1996) describe families as "goal directed, self-correcting, dynamic, interconnected systems that both affect and are affected by their environment and by qualities within the family system itself” (p. 281).

For the past 70 - 80 years professionals assumed that children with disabilities inevitably damage their families. Research assumed these children created a high degree of pathology in their family functioning (Ferguson, 2002). A family including a child with a developmental disability was even considered to be a disabled family (Glidden, 1993). Because these families report increased pressure and demands along with added stress and challenges (Dyson, 1996; Fuller \& Rankin, 1994; Mactavish et al., 1997), researchers assumed they were lower functioning. Researchers have just recently begun to consider the more positive or growth-promoting effects a child with a disability can have on the family (Baker et al., 2002).

Until recently, research reported mixed results for family functioning in families that include children with developmental disabilities (Summers et al., 2005). Some reported these families as malfunctioning (Kronick, 1976) and deviating from the normal range of family cohesion and adaptability (Michaels \& Lewandowski, 1990) while others reported them as having adaptational profiles resembling, in range and number, those 
profiles of families with children without disabilities (Baxter, Cummins, \& Polak, 1995; Krauss \& Seltzer, 1993). The most recent researchers agree that most families with a child with a disability adjust positively and cope effectively with the added demands of raising a child with a developmental disability (Blacher, 2001; Ferguson, 2002; Taunt \& Haustings, 2002). In fact, family functioning in families with children with disabilities is similar to traditional families with children who achieve at normal levels.

Families of children with learning disabilities and families with children who achieve at normal levels are similar in their levels of parental stress and family functioning (Dyson, 1996). Families with children with learning disabilities have positive and cohesive family relationships and use rules for operating the family routine. Increased parental stress, emphasis placed on personal growth, and altered routines, are disadvantages for these families but they do not cause family dysfunction. Cahill and Glidden (1996) found these families with children who have disabilities function at or near normal levels based on families in general. In fact, according to Ferguson (2002), an increasingly dominant body of research has found patterns of overall adjustment and well-being to be similar in groups of families with and without children with disabilities, with some developmental differences over the family life course. Many parents go through a transformative process moving from an initial appraisal of their child's disability as a source of grief and trauma to a positive appraisal of their child and his/her impact on the family and on them personally (Barry \& Singer, 2001). Overall, families with children with disabilities function at the same level as traditional families without children with disabilities (Blacher, 2001; Ferguson, 2002; Taunt \& Haustings, 2002). 
Many parents are able to adapt to the special care demands of their children with disabilities, resulting in parental adaptation rather than parental dysfunction (Roach, Orsmond, \& Barratt, 1999). There is, however, a clear need exists to identify what behaviors are present among families who function at high levels even when faced with the high demands, great challenges, and increased stress that comes with having a child with a disability.

Family leisure involvement is consistently related to family functioning and quality of family life among traditional families (Hawks, 1991; Holman \& Epperson, 1989; Orthner \& Mancini, 1991; Zabriskie \& McCormick, 2001). Scholars also report that family leisure contributes to family functioning among families with different structures such as those with transracial adoptive children (Freeman \& Zabriskie, 2003; Zabriskie \& Freeman, 2004), single-parent families (Smith et al., 2004), and Hispanic families living in the United States (Christenson et al., in press). Studies among families with children who have developmental disabilities have reported similar findings (Mactavish \& Schleien, 1998; Mactavish \& Schleien, 2004; Scholl et al., 2003).

Families that include a child with a disability report leisure as very important to them and perceive joint leisure as a mode of promoting overall quality of life, and helping family members learn life skills (Mactavish \& Schleien, 1998). While families participate in leisure, their communication is enhanced and the resulting interactions are beneficial in increasing family unity. In families with high levels of stress (i.e., many families with children with developmental disabilities), this correlation between family functioning and family leisure may be vital for helping families function at a healthy level. 
Family Leisure in Families of Children with Developmental Disabilities

Greater understanding of family leisure in families that include children with developmental disabilities is needed (Mactavish \& Schleien, 2004). Much of the research on families with children with developmental disabilities has focused on identifying and describing the leisure patterns of these families. There are differences between the recreation patterns in families that include a child with a developmental disability and families studied previously who did not include a child with a disability (Mactavish et al., 1997). Families with a child who has a disability usually engaged in leisure involving two or more, but not all family members. Previous research concluded that most family leisure occurs within the home (United Media, 1982), but according to and Mactavish and Schleien (1997) family leisure in families with children with developmental disabilities occurred as frequently in the community setting as in the home.

Family involvement in community leisure is very important for people with disabilities. Parents and siblings of children with disabilities know the strengths, weaknesses, and preferences of the child with the disability and therefore they can best help meet the needs of that child. As families of children with disabilities participate in leisure together, the child with the disability is seen as a son or daughter, a brother or sister, rather than just someone with a disability; they are viewed in a holistic manner (Heyne \& Schleien, 1997). Therefore, people with disabilities benefit greatly when their families are involved with them in community leisure.

Research (Scholl et al., 2003) shows that outdoor recreation experiences specifically are beneficial to families of children with developmental disabilities because 
they increase knowledge and confidence in recreation participation as a family, improved family relationships, and improved connectedness with people outside the family. Parents of children with disabilities face challenges categorically similar to a typical family such as a limited amount of discretionary money, balancing the needs of all family members, supervision of children, energy, and knowledge, and/or skills; however, for parents of children with developmental disabilities, medical needs stand out, economic needs are more extensive, care-giving demands are greater physically, and the facilitation of appropriate social interactions are both physically and emotionally draining. The constraints on these families limit the number of family recreation options (Scholl et al.). Inclusive outdoor experiences “enhance family satisfaction, especially for families that are identified as cohesive and adaptable to change” (p. 52), but families that have "a structured or rigid family system are much less likely to show an increase in family satisfaction” (p. 52) after participating in outdoor recreation.

Participation in leisure as a family rather than leisure individually may be more significant to children with disabilities than to children without disabilities (Horna, 1994). Parents of children with disabilities view family leisure as "highly important and beneficial for enhancing quality of family life and promoting development of life-long leisure skills and interests” (Mactavish \& Schleien, 2004, p. 137). Siblings without disabilities seem to adopt individual leisure patterns by their adolescence, but children with disabilities rely heavily on family recreation into early adulthood and sometimes even longer (Horna, 1994). Although family leisure is very important for the whole family, parents feel it is particularly important for the children with disabilities because it 
is not only "a vehicle for skill and self development, but offer(s) the most accepting and potentially enduring leisure and social outlet for their children with a disability” (Mactavish \& Schleien, 2004, p. 137). As a result, much leisure in families with children who have disabilities has a strong child-centered focus, and mothers participate most often with their children in these activities (Mactavish \& Schleien, 1997; Mactavish et al., 1997). Family leisure is not a stress-coping strategy for these families because it often increases the stress, but the benefits of family leisure seem to surpass the negative aspects of increased stress. Family leisure is greatly valued by both parents and children with disabilities (Horna, 1994; Mactavish \& Schleien, 2004).

\section{Family Leisure}

Leisure professionals suggest that today, "leisure is the single most important force developing cohesive, healthy relationships between husband and wives and between parents and their children” (Couchman, 1988, as cited in Zabriskie, 2001, p. 30). Studies concerned with leisure in the family were first performed in the 1930s (Hawks, 1991). Since that time they have improved in both their theoretical framework and in their statistical analysis. Current studies and new theoretical models in family research “provide greater understanding and vital direction for the development and provision of services that are likely to strengthen families” (Zabriskie, 2001, p. 30). In 1998, Orthner (1998) criticized parks and recreation professionals for not committing sufficient time and resources to family leisure and its value for family togetherness. He then went on to challenge them to focus on the most vital institution in society, the family, in order to 
strengthen it. Since this challenge, interest in family leisure has increased significantly (Zabriskie, 2001).

Research consistently finds positive relationships between family leisure involvement and positive family functioning (Hawks, 1991; Holman \& Epperson, 1989; Orthner \& Mancini, 1991; Zabriskie \& McCormick, 2001). Family leisure plays a vital role in “family cohesion, adaptability, and communication” (Zabriskie \& McCormick, 2001, p. 282). Society is focusing on the family again and placing importance on spending quality time together and strengthening relationships. Therapeutic recreation and leisure research has also begun to address family issues. In treatment, recreation therapists address family needs and often adopt improving the quality of family life as their main intervention goal (Zabriskie, 2003).

There is a positive relationship between family leisure involvement and family functioning when measured from the perspectives of a child, a parent, and the family (Zabriskie, 2000). According to Shaw (1999), parents view family leisure as an occasion for increased family functioning in the areas of communication, bonding, child development, and learning. In fact, a "significant positive relationship between family leisure involvement and family functioning” (Freeman \& Zabriskie, 2003, p. 86) has been found in families with adopted children of color. These families indicate that family leisure involvement in every day, low cost, accessible, home-based activities are the most powerful predictor of family functioning (Freeman \& Zabriskie, 2003). Furthermore, one study found families who participate in challenging outdoor recreation have reduced levels of conflict because they are more willing to work together through disagreements 
and problems; this is a result of increased trust, support, kindness, affection, interaction, and communication (Huff, Widmer, McCoy, \& Hill, 2003).

Until recently, however, scholars stated that "the nature of the relationship (between family leisure and aspects of family functioning) (was) still poorly understood” (Freeman \& Zabriskie, 2003, p. 75). One of the weaknesses in early research was that married couples were examined and then the findings were generalized to the entire family. Another problem involved leisure being “operationalized in a simplistic and inconsistent manner. Measurement has included any time spent together, as well as lists of activities placed into categories with no theoretical basis” (Zabriskie \& McCormick, 2001, p. 283). The lack of theoretical framework in early research resulted in “idiosyncrasies of the investigation at hand” (Orthner \& Mancini, 1991, p. 299). This has been recognized by other scholars and a call for more theory based research has resulted (Hawks, 1991; Holman, \& Epperson, 1989; Orthner \& Mancini, 1990). “It is imperative to identify and test theoretical models of family leisure that could provide the basis for strengthening measurement, generating hypotheses, and interpreting results when examining family leisure” (Zabriskie \& McCormick, 2001, p. 283).

The family systems theoretical perspective provides a sound avenue whereby the relationship between family and leisure can be examined (Orthner \& Mancini, 1991). The family systems theory focuses on family dynamics, which include power, relations, structures, boundaries, communications patterns, and roles (Rothbaum, Rosen, Ujiie, \& Uchida, 2002). Within this framework, family behavior is best understood by viewing the family as a unit rather than as individual parts. Changes in individuals affect the family 
system's behavior as a whole, just as changes in the system affect each individual family member's behavior (White \& Klein, 2002). Zabriskie and McCormick (2001) summarize the family systems theory by referring to Klein and White's (1996) work. They state that the family systems theory "holds that families are goal directed, self-correcting, dynamic, interconnected systems that both affect and are affected by their environment and by qualities within the family system itself” (p. 281).

Olson’s (1993) Circumplex Model of Marital and Family Systems is a well established model commonly used to describe the family systems framework. This model was developed to bridge the gap often present between research, theory, and practice (Olson, 1993). McCormick and Zabriskie (2001) suggest that all three dimensions of Olson’s (1986) Circumplex Model (cohesion, adaptability, and communication) are facilitated through family leisure involvement. They provided preliminary evidence to support the use of the Core and Balance Model of Family Functioning for exploring family leisure relationships (Zabriskie, 2000). “Both core and balance leisure patterns (are) significantly related to family cohesion and adaptability” (p. 286). This model is grounded in family systems theory and implies a direct relationship between family leisure patterns and family cohesion and adaptability (Zabriskie \& Freeman, 2004). Core and Balance Model of Family Leisure Functioning

The Core and Balance Model of Family Functioning has been used frequently in recent research addressing family leisure and family functioning (Freeman \& Zabriskie, 2003; Zabriskie, 2000, 2001; Zabriskie \& Freeman, 2004; Zabriskie \& McCormick, 2001, 2003). Researchers using this model have continually found a positive relationship 
between family leisure involvement and successful family functioning involving family cohesion and adaptability (Zabriskie \& McCormick, 2001).

The Core and Balance Model combines Iso-Ahola’s (1984) idea of a need for both stability and change with Kelly's (1999) idea of two different styles of leisure behavior. Iso-Ahola (1984) states that individuals have a tendency to "seek both stability and change, structure and variety, and familiarity and novelty in one’s leisure” (p. 98). People meet their needs for stability and change through their leisure activities (Zabriskie \& Freeman, 2004). According to Kelly $(1996,1999)$, individuals try to obtain two different styles or patterns of leisure behavior throughout their life. In one style, leisure is consistent, accessible, and persisted in throughout the life course and in the other leisure has variety, is less accessible, and changes throughout the life course. These concepts concerning leisure behaviors for individuals also apply to families. Zabriskie and Freeman (2004) claim, according to the systems theory, in order for a family to function effectively, it "must meet the need for stability in interactions, structure, and relationships, as well as a need for novelty in experience, input, and challenge” (p. 54). Families as well as individuals search for a balance between stability and change through their leisure.

The Core and Balance Model of Family Leisure Functioning identifies two basic categories of leisure patterns; core and balance. These core and balance leisure patterns meet the needs for stability and change within a family system (Zabriskie and McCormick, 2001). Core activities are usually common and participated in frequently (every day), low cost, home based, require little planning, and are spontaneous. These 
activities provide a safe and positive context for family members to form cohesion and closeness (Zabriskie \& Freeman, 2004). Balance activities, on the other hand, are less frequent or common, usually require more time, effort, money, and planning, and are longer in duration. These activities provide opportunities for novelty and unpredictability and as a result help family members to negotiate and adapt together (Zabriskie \& Freeman, 2004).

This model indicates that core family leisure patterns provide opportunities for families to meet their need for stability which in turn increase their cohesion while balance leisure patterns provide families with opportunities to meet their need for novelty and change which increases their adaptability. Olson (1986) suggests that a balance between family cohesion and adaptability is a key element for healthy functioning families. According to this model, as family leisure participation increases, family functioning should also increase.

Findings among traditional families consistently support the Core and Balance Model of Family Leisure Functioning (Zabriskie, 2000; Zabriskie \& McCormick, 2001, 2003) when examined from a parent, youth, or family perspective. Findings from a known group study examining families with transracial adoptive children also find clear relationships between core and balance family leisure involvement and aspects of family functioning and provide "vital construct related evidence of validity for the model itself" (Zabriskie \& Freeman, 2004, p. 70). Furthermore, researchers conclude that their findings provide “empirical support for the predictive ability of a theoretical model of family leisure functioning” (p. 69). Other known group studies also report similar findings when 
examining single-parent families (Smith et al., 2004) and families with a child in mental health treatment and call for more known group studies with different types of families including families with children with developmental disabilities.

The Core and Balance Model appears to offer a sound theoretical framework from which to examine family leisure functioning among a larger sample of families that include children with developmental disabilities. It suggests that if such families function at similar levels as families without children with disabilities as the literature suggests (Cahill \& Glidden, 1996; Ferguson, 2002), there will be a similar relationship with family leisure involvement as well. In an effort to respond to the need for a broader examination of the family leisure relationship among such families as well as to respond to the call for more known group studies, the purpose of this study is to examine the contribution of family leisure involvement to the family functioning of families with children with developmental disabilities.

\section{Summary}

Olson (1993) uses the Family systems theory in his Circumplex Model of Marital and Family Systems to identify family functioning in terms of cohesion and adaptability. Families with children with developmental disabilities often have higher stress levels and greater demands such as physical, emotional, economical, medical, and care-giving demands, but they are able to positively adapt to having a child with a disability, and function at similar levels as do traditional families without children with disabilities. Recently, a number of studies examining family leisure among families with children with developmental disabilities have emerged (Mactavish \& Schleien, 1997, 1998, 2004; 
Scholl et al., 2003) indicating that family leisure involvement is important for the successful functioning of these families, yet broader, more representative samples are a vital step to further this line of research. Mactavish and Schleien (2004) declare that "recreation in families that include children with developmental disabilities is a neglected area of research in both disability studies and leisure studies” (p. 125). Further research along these lines would "improve understanding of family life, factors that contribute to effective family functioning, and the role of leisure in this process” (Mactavish \& Schleien, 2004, p. 125).

The Core and Balance Model of Family Leisure Functioning predicts that families with children with developmental disabilities who are high-functioning, with higher levels cohesion and adaptability will also have higher levels of family leisure involvement. Adding to this line of research with this framework of family leisure functioning will strengthen the foundation previous researchers have established and provide findings from a larger sample of families with children with disabilities. It is anticipated that the findings will have considerable implications for families with children with developmental disabilities, professionals, services, and agencies that work with these families, and may provide direction for those families within this category who may be struggling under their high levels of demand and stress. Therefore, the purpose of this study is to examine the contribution of family leisure involvement to the family functioning of families with children with developmental disabilities. 


\section{Chapter 3}

\section{Methods}

The problem of the study is to examine the contributions of family leisure involvement to family functioning in families that include children with developmental disabilities. Included in this chapter are the following: (a) sample, (b) instrumentation, (c) data collection procedures, and (d) analysis.

\section{Sample}

A convenience sample will be used in this study. It will include a minimum of 100 families with children with developmental disabilities consisting of a mother, and/or father, or guardian, at least one child with a developmental disability living in their home, and at least one dependent child 10 to 17 years of age. A developmental disability is defined as “A severe and chronic disorder involving mental and / or physical impairment that originates before age 22. Such a disability is likely to persist indefinitely, and will cause substantial functional limitation in at least three of the following seven areas of major life activities: self-care, receptive and expressive language, learning, mobility, selfdirection, capacity for independent living, economic self-sufficiency” (Mactavish et al., 1997, p. 26).

The restricted age range will be implemented to involve children at a cognitive development level with the ability to use abstract thinking necessary for understanding and completing the survey instrument (Zabriskie \& McCormick, 2003). Taylor (2005) intended to question youth ages 11-15, but youth between the ages of 11-19 responded. When she compared the means of older youth (16-19 years) results with younger youth 
(11-15 years) she found no significant differences so therefore this study, like her, will employ a broad age range (10-17 years) for the youth. As Zabriskie and Freeman (2004) point out, "scholars have called studies for special needs adoptive family systems to go beyond a parent only perspective and examine a child's perspective of family functioning as well” (p. 57). In order to gather family members’ perspectives of their functioning, this study will collect data from a dependent child as well as a parent. This will provide two perspectives from each family on their family functioning and leisure.

The families will be found through agencies, conferences, parent support groups, associations, clubs, and schools throughout United States and Canada. Snowballing, associates of the researchers, and their referrals will also be used in an effort to obtain a broad representative sample. The results will not be generalized to all families with children who have a developmental disability, but will only reflect the families who will participate in the study.

\section{Instrumentation}

The research instrument will include three sections: (a) Family Adaptability and Cohesion Scales (FACES II), which provides a measure of the family's perception of their family cohesion, family adaptability, and overall indicators of family functioning (Olson et al., 1992), (b) Family Leisure Activity Profile (FLAP), which provides a measure of core, balance, and overall family leisure involvement (Zabriskie \& McCormick, 2001), and (c) relevant socio-demographic questions including a scale adapted by Dyches (2000) based upon the definition, classification, and systems of support manual of the American Association on Metal Retardation (1992) . 
FACES II. The Family Adaptability and Cohesion Scales (FACES II) is a 30-item scale that measures the perceptions of family cohesion and adaptability that determine family functioning based on Olson’s Circumplex Model (Olson, 1986). This scale contains 16 questions that measure cohesion and 14 questions that measure adaptability. Because it was designed to measure family dynamics, it focuses on system characteristics of family members presently living at home. This instrument uses a Likert scale ranging from 1 (almost never) to 5 (almost always) for the respondents to use in answering the questions. Scores for family cohesion and family adaptability are calculated based on a scoring formula that accounts for reverse coded questions. After obtaining total cohesion and total adaptability scores, corresponding $1-8$ values will be assigned based on the linear scoring interpretation of Olson et al. (1992). These two scores will be averaged in order to obtain the family type score which is used as an indicator of overall family functioning. The FACES II scale has acceptable psychometric properties of validity and reliability. Cronbach Alpha coefficients are reported as .78 and .79 for adaptability and .86 and .88 for cohesion (Olson et al.).

FLAP. The Family Leisure Activity Profile (FLAP) is an activity inventory which measures family leisure involvement based on the Core and Balance Model of Family Leisure Functioning (Zabriskie, 2000). Participants identify activities performed with family members across 16 activity categories. Eight questions represent core family leisure patterns and the other eight represent balance family leisure patterns. Each question asks if the respondent participates in the activity with family members. If the answer is yes then the respondent is then asked the estimated frequency and duration for 
the activity. They also indicate on a five-point Likert scale their satisfaction with these family activities ( 1 = very dissatisfied and 5 = very satisfied $)$.

An index score is found for each question by multiplying duration and frequency. The core index score is found by summing the index scores of questions 1-8, and the balance index score is calculated by summing the index scores of questions 9-16. The total family leisure score is calculated by summing the core and balance index scores (Zabriskie \& McCormick, 2001). The FLAP also has acceptable psychometric properties. It has been shown to have construct and content validity, inter-rater reliability, and testretest reliability for core $(r=.74)$, balance $(r=.78)$, and total family leisure involvement $(\mathrm{r}=.78)$ (Zabriskie, 2001).

Demographics. Socio-demographic questions will be included to determine underlying characteristics of the sample. These will include age, gender, marital status, ethnicity, religion, state or country of residence, annual family income, family size, age of all children, relationship of parents to children (i.e., biological, step parent, adoptive parent, foster parent, legal guardian), length of time the child with a developmental disability has been in the family, IQ level of child with disability, type of developmental disability, and adaptive skills / levels of support needed by the child with the developmental disability.

Parents will complete a scale consisting of 11 questions that describes their child with a developmental disability. This scale was developed by Dyches (2000) based upon the definition, classification, and systems of support manual of the American Association on Mental Retardation (1992). The American Association on Mental Retardation has an 
interdisciplinary membership with strong international ties. In order to develop the manual on mental retardation, input was gathered from, "the general membership of the Association, members represented in leadership positions, members in divisions and special interest groups, individuals representing sister organizations and agencies, and other colleagues in the field” (American Association on Mental Retardation, 1992, p. x). The adapted scale (Dyches, 2000) focuses on the levels of support needed by the child with a disability to participate in natural environments. For each of the 11 adaptive skills, parents choose from four levels of support: intermittent, limited, extensive, or pervasive. Intermittent supports are given “on an 'as-needed’ basis, are temporary, infrequent or short-termed, and are needed in few settings. Limited supports are provided on a regular basis for a short period of time, in several settings. Extensive supports are needed regularly in several settings and may extend over long periods of time. Pervasive supports are constant and intense in all settings and may be life-sustaining” (Dyches, Cichella, Olsen, \& Mandleco, 2004, p. 175). This scale has been used successfully in past studies (Dyches, Cichella, Olsen, \& Mandleco, 2004) and has content validity in that it covers not only the seven areas of major life activities from the developmental disability definition used in this study, but it also goes beyond this definition and measures three other areas.

\section{Data Collection Procedures}

An online or paper questionnaire will be used to collect the data beginning June 2006 and will continue until a sample size of at least 100 families is gathered. The participants will be expected to complete the questionnaire on their own after receiving 
the internet location or receiving the paper copy of the questionnaire. Families will be found through parent support groups, organizations, schools throughout Canada and the United States, and snowballing. Associates of the researchers and their referral will also be contacted and asked to participate. At the beginning of the questionnaire, participants will read that by completing the questionnaire they will be consenting to participate. They will also be told that their participation is voluntary, and that they can stop at any time. In order to maintain confidentiality, no questions will ask for personal identification, only demographic questions will be asked. The data will be stored in personal file and on a database and exported to an Excel file that will be protected by a password. Analysis

The statistical package SAS will be used to analyze the data. Data will be reviewed for outliers and missing responses. Three data sets will be compiled: (a) responses of parents, (b) responses of dependent children, and (c) family level measurement (the mean for each family). Descriptive statistics will be used to explore the underlying characteristics of the research variables. Pearson Product Moment zero-order correlations between variables in each of the three data sets will be examined for multicollinearity as well as to identify possible controlling factors that could be included in subsequent multiple regression equations. Socio-demographic variables will be included in the multiple regression models to look at the distinct contributions of family leisure involvement to family functioning. The contributions to family leisure involvement from a perspective of the parent, the youth, and the family will be examined using three block method multiple regressions analysis. The multiple regression 
coefficients will be examined at a .05 alpha level. The relative contribution of each variable in significant models will be determined with standardized regression coefficients (Beta).

To examine the difference in family functioning and family leisure involvement between families that include a child with a developmental disability and a previously collected sample of families that do not include a child with a developmental disability the three data sets will be used: (a) responses of parents, (b) responses of dependents, and (c) family level measurement (the mean for each family). To test for significant differences between samples, an ANCOVA adjusting for significant demographic variables will be used. 


\section{References}

American Association on Mental Retardation. (1992). Mental Retardation: Definition, Classification, and Systems of Supports ( $9^{\text {th }}$ ed.). Washington, D.C.: Author.

Baker, B. L., Blacher, J., Crnic, K. A., \& Edelbrocke, C. (2002). Behaviour problems and parental stress in families of three-year-old children with and without developmental delays. American Journal of Mental Retardation, 107, 433-444.

Barry, L. M., \& Singer, G. H. S. (2001). Reducing maternal psychological distress after NICU experience through journal writing. Journal of Early Intervention, 24, 287297.

Baxter, C., Cummins, R. A., \& Polak, S. (1995). A longitudinal study of parental stress and support: From diagnosis of disability to leaving school. International Journal of Disability, Developmental and Education, 42, 125-136.

Blacher, J. (2001). Transition to adulthood: Mental retardation, families, and culture. American Journal on Mental Retardation, 106, 173-188.

Cahill, B. M., \& Glidden, L. M. (1996). Influence of child diagnosis on family and parental functioning: Down syndrome versus other disabilities. American Journal of Mental Retardation, 10, 149-160.

Christenson, O., Zabriskie, R., Eggett, D., \& Freeman, P. (in press). Family acculturation, family leisure involvement, and family functioning among Mexican-Americans. Journal of Leisure Research, 38(4). 
Dumas, J., Wolf, L., Fisman, S., \& Culligan, A. (1991). Parenting stress, child behavior problems, and dysphoria in parents of children with autism, Down syndrome, behavior disorders, and normal development. Exceptionality, 2, 7-10.

Dyches, T. T. (2000). Child (with Special Needs) Description. Adapted from: American Association on Mental Retardation. (1992). Mental Retardation: Definition, Classification, and Systems of Supports ( $9^{\text {th }}$ ed.). Washington, D.C.: Author.

Dyches, T. T., Cichella, E., Olsen, S. F., \& Mandleco,M. (2004). Snapshots of life: Perspectives of school-aged individuals with developmental disabilities. Research \& Practice for Persons with Severe Disabilities, 29(3), 172-182.

Dyson, L. L. (1996). The experiences of families of children with learning disabilities: Parental stress, family functioning, and sibling self-concept. Journal of Learning Disabilities, 29(3), 280-286.

Ferguson, P. (2002). A place in the family: An historical interpretation of research on parental reactions to having a child with a disability. Journal of Special Education, 36, 126-147.

Freeman, P., \& Zabriskie, R. B. (2003). Leisure and family functioning in adoptive families: Implications for therapeutic recreation. Therapeutic Recreation Journal, 37(1), 73-93.

Fuller, G. B., \& Rankin, R. E. (1994). Differences in levels of parental stress among mothers of learning disabled, emotionally impaired, and regular school children. Perceptual and Motor Skills, 78, 583-592. 
Glidden, L. M. (1993). What we do not know about families with children who have developmental disabilities: Questionnaire on resources and stress as a case study. American Journal of Mental Retardation, 97(5), 481-495.

Hawks, S. R. (1991). Recreation in the family. In S. J. Bahr (Ed.), Family research: A sixty year review, 1930-1990. New York: Lexington Books.

Heyne, L., \& Schleien, S. (1997). Teaming up with parents to support inclusive recreation. Parks \& Recreation, 32(5), 76-81.

Holman, T. B., \& Epperson, A. (1984). Family and leisure: A review of the literature with research recommendations. Journal of Leisure Research, 16, 277-294.

Holman, T. B., \& Epperson, A. (1989). Family and leisure: A review of the literature with research recommendations. Journal of Leisure Research, 16, 277-294.

Horna, J. (1994). The Study of Leisure: An introduction. Toronto, Ontario, Canada: Oxford University Press.

Huff, C., Widmer, M., McCoy, K., \& Hill, B. (2003). The influence of challenging outdoor recreation on parent-adolescent communication. Therapeutic Recreation Journal, 37(1), 18-37.

Iso-Ahola, S. (1984). Social psychological foundations of leisure and resultant implications for leisure counseling. In E. T. Dowd (Ed.), Leisure counseling: Concepts and applications (pp. 97-125). Springfield, IL: Charles C. Thomas.

Kelly, J. R. (1996). Leisure 3rd Edition. Needham Heights, MA: Allyn \& Bacon. 
Kelly, J. R. (1999). Leisure behaviors and styles: Social, economical, and cultural factors. In E. L. Jackson \& T. L. Burton (Eds.), Leisure Studies: Prospects for the twentyfirst century (pp. 135-150). State College, PA: Ventura.

Klein, D. M., \& White, J. M. (1996). Family theories: An introduction. Thousand Oaks, CA: Sage Publications, Inc.

Krauss, M. W., \& Seltzer, M. M. (1993). Current well-being and future plans of older care giving mothers. The Irish Journal of Psychology, 14(1), 48-63.

Kronick, D. (1976). Three families: The effect of family dynamics on social and conceptual learning. San Rafael, CA: Academic Therapy.

Kwai-sang, M., \& Li-Tsang, C. W. P. (1999). Adjustment in adaptation in parents of children with developmental disability in two-parent families: A review of the characteristics and attributes. British Journal of Developmental Disabilities, 45, 38-51.

Landesman, S., \& Vietze, P. (Eds). (1987). Living environments and mental retardation. Washington, DC: American Association on Mental Retardation.

Lashua, B., Widmer, M., \& Munson, W. (2000). Some well deserved 'R \& R'. Parks \& Recreation, 35(5), 56-63.

Mactavish, J., \& Schleien, S. (1997). Patterns of family recreation in families that include children with a developmental disability. Journal of Leisure Research, 29(1), 2126.

Mactavish, J., \& Schleien, S. (1998). Playing together growing together: Parents' 
perspectives on the benefits of family recreation in families that include children with a developmental disability. Therapeutic Recreation Journal, 32(3), 207-230. Mactavish, J., \& Schleien, S. (2004). Re-injecting spontaneity and balance in family life: parents’ perspective on recreation in families that include children with developmental disability. Journal of Intellectual Disability Research 48(2), 123141.

Mactavish, J., Schleien, S., \& Tabourne, C. (1997). Patterns of family recreation in families that include children with a developmental disability. Journal of Leisure Research, 29(1), 21-46.

Margalit, M., \& Heiman, T. (1986). Family climate and anxiety in families with learning disabled boys. Journal of the American Academy of Child Psychiatry, 25, 841846.

Michaels, C. R., \& Lewandowskie, L. J. (1990). Psychological adjustment and family functioning of boys with learning disabilities. Journal of Learning Disabilities, 23, 446-450.

Olson, D. H. (1986). Circumplex model VII: Validation studies and FACES III. Family Process, 25, 337-351.

Olson, D. H. (1993). Circumplex model of marital and family systems: Assessing family systems. In F. Walsh (Ed.), Normal Family Processes (pp. 104-137). New York: Guilford Press.

Olson, D. H. (2000). Circumplex model of marital and family systems. Journal of Family Therapy, 22(2), 144-167. 
Olson, D. H., Portner, J., and Bell, R. (1982). FACES II: Family adaptability and cohesion evaluation scales. St. Paul, MN: Family Social Science, University of Minnesota.

Olsson, M. B., \& Hwang, C. P. (2001). Depression in mothers and fathers of children with intellectual disabilities. Journal of Intellectual Disability Research, 45, 535543.

Orthner, D. K. (1998). Strengthening today’s families: A challenge to parks and recreation. Parks and recreation, 33(3), 87-98.

Orthner, D. K., \& Mancini, J. A. (1990). Leisure impacts on family interaction and cohesion. Journal of Leisure Research, 22(2), 125-137.

Orthner, D. K., \& Mancini, J. A. (1991). Benefits of leisure for family bonding. In B. L. Driver, P. J. Brown, \& G. L. Peterson (Eds.). Benefits of leisure (pp. 215-301). State College, PA: Venture.

Powers, L. E., \& Singer, G. H. S. (1996). Reflections on competence: Perspective of successful adults. Baltimore: Brooks.

Roach, M. A., Orsmond, G. I., \& Barratt, M. S. (1999). Mothers and fathers of children with Down syndrome: Parental stress and involvement in childcare. American Journal on Mental Retardation, 104(5), 422-436.

Rothbaum, F., Rosen, K., Ujiie, T., \& Uchida, N. (2002). Family systems theory, attachment theory, and culture. Family Process, 41, 328-350. 
Scholl, K., McAvoy, L., Rynders, J., \& Smith, J. (2003). The influence of inclusive outdoor recreation experience on families that have a child with a disability. Therapeutic Recreation Journal, 37(1), 38-57.

Shaw, S. (1999). Purposive leisure: Examining parental discourses on family activities. In W. Stewart \& D. Sandahl (Eds.), Abstracts from the 1999 Symposium on Leisure Research (p. 7), Ashburn, VA: National Park and Recreation Association.

Singer, G. H. S. (2002). Suggestions for a pragmatic program of research on families and disability. Journal of Special Education, 36(3), 148-154.

Smith, K. M., Taylor, S., Hill, B., \& Zabriskie, R. B. (2004). Family functioning and leisure in single-parent families. Abstracts from the 2004 Leisure Research Symposium. Ashburn, VA: National Recreation and Parks Association.

Summers, J., Poston, D., Turnbull, A., Marquis, J., Hoffman, L., Mannan, H., \& Wang, M. (2005). Conceptualizing and measuring family quality of life. Journal of Intellectual Disability Research, 49(10), 777-783.

Taunt, H., \& Hastings, R. (2002). Positive impact of children with developmental disabilities on their families: A preliminary study. Education and Training in Mental Retardation and Developmental Disabilities, 37, 410-420.

Taylor, S. (2005). Praying playing and happy families: An examination of the relationship between family religiosity, family recreation, and family functioning. Unpublished master’s thesis, Brigham Young University, Provo, UT.

United Media Enterprises Report on Leisure in America. (1982). Where does time go? New York: United Media Enterprises. 
Warfield, M., Krauss, M., Hauser-Cram, P., Upshur, C., \& Shonkoff, J. (1999). Adaptation during early childhood among mothers of children with disabilities. Developmental and Behavioral Pediatrics, 20, 9-16.

White, J. M., \& Klein, D. M. (2002). Family theories: An introduction, Second Edition. Thousand Oaks, CA: Sage.

Zabriskie, R. B. (2000). An examination of family and leisure behavior among families with middle school aged children. Unpublished doctoral dissertation, Indiana University, Bloomington, Indiana.

Zabriskie, R. B. (2001). Family recreation: How can we make a difference? Parks and Recreation, 36(10), 30-42.

Zabriskie, R. B. (2003). Introduction to the special issue on the family: A refocus on family. Therapeutic Recreation Journal, 37(1), 15-17.

Zabriskie, R. B., \& Freeman, P. (2004). Contributions of family leisure to family functioning among transracial adoptive families. Adoption Quarterly, 7(3), 49-77.

Zabriskie, R. B., \& McCormick, B. P. (2001). The influences of family leisure patterns on perceptions of family functioning. Family Relations: Interdisciplinary Journal of Applied Family Studies, 50(3), 66-74.

Zabriskie, R. B., \& McCormick, B. P. (2003). Parent and child perspectives of family leisure involvement and satisfaction with family life. Journal of Leisure Research, 35(2), 163-189. 
Appendix A-1a

Informed Consent 
Consent to be a research subject - Parent

Thank you for participating in our research! Your participation is greatly appreciated. Please complete the following questionnaire. This questionnaire will take approximately 20 minutes to complete for both you and your adolescent child (ages 10-17). The intent of this study is to examine recreation involvement in families that include a child with a developmental disability. Results may benefit families through a better understanding of the relationship between family recreation and strong families. We request that a parent complete the first portion of the questionnaire and an adolescent child (ages 10-17) without a disability complete the second portion. If there is no adolescent child (ages 1017) please complete the first portion only. There are minimal risks for participation in this study. Participation is optional and completely voluntary. You have the right to withdraw at any time without penalty or you may choose to refuse to participate entirely. There will be no reference to your identification at any point in the research. If you have questions regarding this study please contact Dr. Ramon Zabriskie at (801) 422-1667. If you have questions regarding your rights as a participant please contact Dr. Renea Beckstrand, Chair of the Institutional Review Board for Human Subjects at Brigham Young University (422 SWKT, BYU, Provo, UT 84602; phone [801] 422-3873; email renea_beckstrand@byu.edu).

\section{By clicking the "next" button, I am consenting to participate for me and my adolescent child.}

Click the "next" button to continue. 
Consent to be a research subject - Youth

This is the YOUTH portion of the survey. It should be completed by a youth ages 10-17.

Please complete the following questionnaire. This questionnaire will take approximately 10 minutes to complete. There will be questions about your family leisure participation and your family life satisfaction. Participation in this questionnaire is optional and completely voluntary. You have the right to stop at any time or refuse to participate entirely.

C I would like to participate

E I do not want to participate (click the "back" button on your browser and answer "no" to the question "do you have a youth between the ages of 10-17")

\section{Family Leisure Activity Profile}

The following questions ask about the activities you do with family members. Please refer to the last year or so. These questions ask about groups of activities, so try to answer in terms of the group as opposed to any one specific example. This may require you to "average" over a few different activities. Don't worry about getting it exactly "right." Just give your best estimate.

\section{Symbol Key:}

$<$ = less than (e.g. $<1$ hour reads "less than one hour")

$>=$ more than (e.g. $>10$ hours reads "more than ten hours")

Push the "next" button to start the survey. 
Appendix A-1b

Family Leisure Activity Profile 


\section{Family Leisure Activity Profile}

\section{(FLAP)}

The following questions ask about the activities you do with family members. Please refer to the last year or so. These questions ask about groups of activities, so try to answer in terms of the group as opposed to any one specific example. This may require you to "average” over a few different activities. Don’t worry about getting it exactly "right.” Just give your best estimate.

Take a moment to look at the example below. This will give you some instruction on how to fill in your answers.

QUESTION: Do you participate in home-based activities (for example watching TV/videos, listening to music, reading books, singing, etc.) with family members?

First do you do these activities?

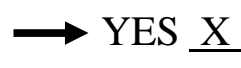

NO

\begin{tabular}{|l|l|}
\hline \multicolumn{2}{|c|}{ If YES how often? } \\
\hline At least daily & \\
\hline At least weekly & $\mathrm{x}$ \\
\hline At least monthly & \\
\hline At least annually & \\
\hline
\end{tabular}

do these

activities?

\begin{tabular}{|r|r|r|r|r|r|}
\hline \multicolumn{5}{|c|}{ For about how long per time? (check only one) } \\
\hline$<1$ hour & 1-2 hrs & 2-3 hours & $\mathrm{x}$ \\
\hline 3-4 hours & & 4-5 hours & & 5-6hours & \\
\hline 6-7 hours & & 7-8 hours & & 8-9 hours & \\
\hline 9-10 hours & & $>10$ hours & & $>1$ day & \\
\hline & $\uparrow$ & & & \\
\hline
\end{tabular}

Then, about how long, on average, do you typically do this type of activity each time you do it?

Last, how satisfied are you with your participation with family members in these activities? Please answer this question EVEN IF YOU DO NOT do these activities with your family.

How satisfied are you with your participation with family members in these activities? (please circle one)

Very

Dissatisfied
2
1

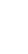

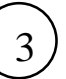

Very

Satisfied 


\section{$\uparrow$}

\begin{tabular}{l} 
Symbol Key \\
$<=$ less than (e.g. $<1$ hour reads "less than one hour") \\
$>=$ more than (e.g. $>10$ hours reads " more than ten hours") \\
\hline
\end{tabular}

\section{Do you have dinners, at home, with family members?}

YES NO -
\begin{tabular}{|l|l|}
\hline If YES how often? \\
\hline At least daily & \\
\hline At least weekly & \\
\hline At least monthly & \\
\hline At least annually & \\
\hline
\end{tabular}

How satisfied are you with your participation or lack of participation, with family members in these activities? (please circle one)

Very

Dissatisfied
1

2

3

4

Very

Satisfied 
2. Do you participate in home-based activities (for example watching TV/videos, listening to music, reading books, singing, etc.) with family members?

YES _ NO N

\begin{tabular}{|c|c|c|c|}
\hline If YES how often? & \multicolumn{3}{|c|}{ For about how long per time? (check only one) } \\
\hline At least daily & $<1$ hour & $1-2 \mathrm{hrs}$ & $2-3$ hours \\
\hline At least weekly & 3-4 hours & 4-5 hours & 5-6hours \\
\hline At least monthly & 6-7 hours & 7-8 hours & 8-9 hours \\
\hline At least annually & 9-10 hours & $>10$ hours & $>1$ day \\
\hline
\end{tabular}

How satisfied are you with your participation with family members in these activities? (please circle one)

Very

Dissatisfied
1
Very

Satisfied

5 
3. Do you participate in games (for example playing cards, board games, video games, darts, billiards, etc.) with family members?

YES _

\begin{tabular}{|c|c|c|c|}
\hline If YES how often & \multicolumn{3}{|c|}{ For about how long per time? (check only one) } \\
\hline At least daily & $<1$ hour & $1-2 \mathrm{hrs}$ & $2-3$ hours \\
\hline At least weekly & 3-4 hours & 4-5 hours & 5-6hours \\
\hline At least monthly & 6-7 hours & 7-8 hours & 8-9 hours \\
\hline At least annually & 9-10 hours & $>10$ hours & $>1$ day \\
\hline
\end{tabular}

How satisfied are you with your participation with family members in these activities? (please circle one)

Very

Dissatisfied

1
2

3
Very

Satisfied

5

\section{Do you participate in crafts, cooking, and/or hobbies (for example drawing, scrap books, baking cookies, sewing, painting, ceramics, etc.) with family members?}

YES _ NO N

\begin{tabular}{|c|c|c|c|}
\hline If YES how often? & \multicolumn{3}{|c|}{ For about how long per time? (check only one) } \\
\hline At least daily & $<1$ hour & $1-2 \mathrm{hrs}$ & $2-3$ hours \\
\hline At least weekly & 3-4 hours & 4-5 hours & 5-6hours \\
\hline At least monthly & 6-7 hours & 7-8 hours & 8-9 hours \\
\hline At least annually & 9-10 hours & $>10$ hours & $>1$ day \\
\hline
\end{tabular}

How satisfied are you with your participation with family members in these activities? (please circle one)

Very

Dissatisfied
2
3
Very Satisfied 
5. Do you participate in home-based outdoor activities (for example star gazing, gardening, yard work, playing with pets, walks, etc.) with family members?

\begin{tabular}{|c|c|c|c|c|}
\hline YES & NO & & & \\
\hline If YES how often? & & \multicolumn{3}{|c|}{ For about how long per time? (check only one) } \\
\hline At least daily & & $<1$ hour & 1-2 hrs & $2-3$ hours \\
\hline At least weekly & & 3-4 hours & 4-5 hours & 5-6hours \\
\hline At least monthly & & 6-7 hours & 7-8 hours & 8-9 hours \\
\hline At least annually & & 9-10 hours & $>10$ hours & $>1$ day \\
\hline
\end{tabular}

How satisfied are you with your participation with family members in these activities? (please circle one)
Very
Dissatisfied
Very
Satisfied
1
2
3
4
5

\section{Do you participate in home-based sport/games activities (for example playing catch, shooting baskets, frisbee, bike rides, fitness activities, etc.) with family members?}

YES NO _
\begin{tabular}{|l|l|}
\hline If YES how often? \\
\hline At least daily \\
\hline At least weekly \\
\hline At least monthly & \\
\hline At least annually & \\
\hline
\end{tabular}

How satisfied are you with your participation with family members in these activities? (please circle one)

Very

Dissatisfied
Very

Satisfied

4

5 
7. Do you attend other family members' activities (for example watching or leading their sporting events, musical performances, scouts, etc.)?

YES _ NO N

\begin{tabular}{|l|l|}
\hline \multicolumn{1}{|c|}{ If YES how often? } \\
\hline At least daily & \\
\hline At least weekly & \\
\hline At least monthly & \\
\hline At least annually & \\
\hline
\end{tabular}

How satisfied are you with your participation with family members in these activities? (please circle one)

Very

Dissatisfied

1

2

3

4

Very

Satisfied

5 
8. Do you participate in religious/spiritual activities (for example going to church activities, worshipping, scripture reading, Sunday school, etc.) with family members?

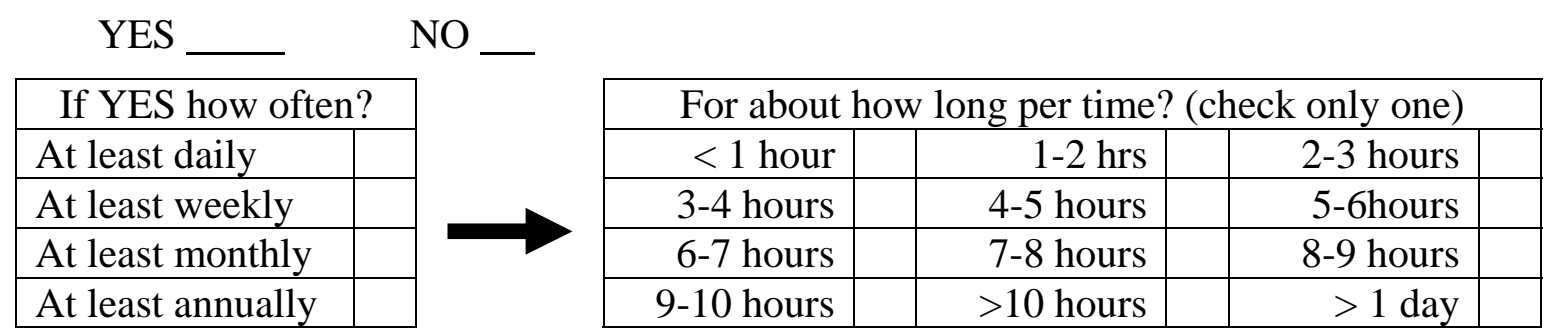

How satisfied are you with your participation with family members in these activities? (please circle one)

Very

Dissatisfied

1
2
3
Very

Satisfied

4

5

9. Do you participate in community-based social activities (for example going to restaurants, parties, shopping, visiting friends/ neighbors, picnics, etc.) with family members?

\begin{tabular}{l} 
YES NO - \\
\begin{tabular}{|l|l|}
\hline If YES how often? \\
\hline At least daily & \\
\hline At least weekly & \\
\hline At least monthly & \\
\hline At least annually & \\
\hline
\end{tabular} \\
\hline \begin{tabular}{|r|r|r|r|r|r|}
\hline For about how long per time? (check only one) \\
\hline 3-4 hours & & 4-5 hours & & 5-6hours & \\
\hline 6-7 hours & & 7-8 hours & & 8-9 hours & \\
\hline 9-10 hours & & $>10$ hours & & $>1$ day & \\
\hline
\end{tabular}
\end{tabular}

How satisfied are you with your participation with family members in these activities? (please circle one)

Very

Dissatisfied
Very

Satisfied 
10. Do you participate in spectator activities (for example going to movies, sporting events, concerts, plays or theatrical performances, etc.) with family members?

\begin{tabular}{|c|c|c|c|c|}
\hline YES & \multirow[t]{2}{*}{$\mathrm{NO}$} & & & \\
\hline If YES how often? & & \multicolumn{3}{|c|}{ For about how long per time? (check only one) } \\
\hline At least daily & & $<1$ hour & $1-2 \mathrm{hrs}$ & $2-3$ hours \\
\hline At least weekly & & 3-4 hours & 4-5 hours & 5-6hours \\
\hline At least monthly & & 6-7 hours & 7-8 hours & 8-9 hours \\
\hline At least annually & & 9-10 hours & $>10$ hours & $>1$ day \\
\hline
\end{tabular}

How satisfied are you with your participation with family members in these activities? (please circle one)

$\begin{array}{ccccc}\begin{array}{c}\text { Very } \\ \text { Dissatisfied }\end{array} & & & & \begin{array}{c}\text { Very } \\ \text { Satisfied }\end{array} \\ 1 & 2 & 3 & 4 & 5\end{array}$

11. Do you participate in community-based sporting activities (for example bowling, golf, swimming, skating, etc.) with family members?

YES NO _
\begin{tabular}{|l|l|}
\hline If YES how often? \\
\hline At least daily & \\
\hline At least weekly & \\
\hline At least monthly & \\
\hline At least annually & \\
\hline
\end{tabular}

How satisfied are you with your participation with family members in these activities? (please circle one)

Very

Dissatisfied

\author{
Very \\ Satisfied
}

1
2

4 


\section{Do you participate in community-based special events (for example visiting} museums, zoos, theme parks, fairs, etc.) with family members?

\begin{tabular}{|c|c|c|c|}
\hline \multicolumn{4}{|c|}{ NO } \\
\hline If YES how often? & \multicolumn{3}{|c|}{ For about how long per time? (check only one) } \\
\hline At least daily & $<1$ hour & $1-2 \mathrm{hrs}$ & $2-3$ hours \\
\hline At least weekly & 3-4 hours & 4-5 hours & 5-6hours \\
\hline At least monthly & 6-7 hours & 7-8 hours & 8-9 hours \\
\hline At least annually & 9-10 hours & $>10$ hours & \\
\hline & 1 day & 8 days & 15 days \\
\hline & 2 days & 9 days & 16 days \\
\hline & 3 days & 10 days & 17 days \\
\hline & 4 days & 11 days & 18 days \\
\hline & 5 days & 12 days & 19 days \\
\hline & 6 days & 13 days & 20 days \\
\hline & One week & Two weeks & $\begin{array}{r}3 \text { or more } \\
\text { weeks }\end{array}$ \\
\hline
\end{tabular}

How satisfied are you with your participation with family members in these activities? (please circle one)

Very

Dissatisfied
Very

Satisfied 
13. Do you participate in outdoor activities (for example camping, hiking, hunting, fishing, etc.) with family members?

YES _ NO N

\begin{tabular}{|l|l|}
\hline \multicolumn{2}{|c|}{ If YES how often? } \\
\hline At least daily & \\
\hline At least weekly & \\
\hline At least monthly & \\
\hline At least annually & \\
\hline
\end{tabular}

\begin{tabular}{|c|c|c|}
\hline \multicolumn{3}{|c|}{ For about how long per time? (check only one) } \\
\hline$<1$ hour & $1-2 \mathrm{hrs}$ & $2-3$ hours \\
\hline 3-4 hours & 4-5 hours & 5-6hours \\
\hline 6-7 hours & 7-8 hours & 8-9 hours \\
\hline 9-10 hours & $>10$ hours & \\
\hline 1 day & 8 days & 15 days \\
\hline 2 days & 9 days & 16 days \\
\hline 3 days & 10 days & 17 days \\
\hline 4 days & 11 days & 18 days \\
\hline 5 days & 12 days & 19 days \\
\hline 6 days & 13 days & 20 days \\
\hline One week & Two weeks & $\begin{array}{r}3 \text { or more } \\
\text { weeks } \\
\end{array}$ \\
\hline
\end{tabular}

How satisfied are you with your participation with family members in these activities? (please circle one)

Very

Dissatisfied

1

2

3

4

Very

Satisfied

5

\section{Do you participate in water-based activities (for example water skiing, jet skiing, boating, sailing, canoeing, etc.) with family members?}

YES _ NO

\begin{tabular}{|l|l|}
\hline \multicolumn{2}{|c|}{ If YES how often? } \\
\hline At least daily & \\
\hline At least weekly & \\
\hline $\begin{array}{l}\text { At least monthly } \\
\text { (during season) }\end{array}$ \\
\hline At least annually & \\
\hline
\end{tabular}

\begin{tabular}{|r|r|r|r|r|}
\hline \multicolumn{5}{|c|}{ For about how long per time? (check only one) } \\
\hline$<1$ hour & $1-2$ hrs & 2 -3 hours & \\
\hline 3-4 hours & $4-5$ hours & 5-6hours & \\
\hline 6-7 hours & $7-8$ hours & & $8-9$ hours & \\
& & & & \\
\hline 9-10 hours & & 10 hours & & \\
\hline 1 day & 8 days & 15 days & \\
\hline 2 days & 9 days & 16 days & \\
\hline 3 days & 10 days & 17 days & \\
\hline 4 days & 11 days & 18 days & \\
\hline 5 days & 12 days & 19 days & \\
\hline 6 days & 13 days & 20 days & \\
\hline
\end{tabular}




\begin{tabular}{|r|r|r|r|r|}
\hline One week & Two weeks & $\begin{array}{r}3 \text { or more } \\
\text { weeks }\end{array}$ \\
\hline
\end{tabular}

How satisfied are you with your participation with family members in these activities? (please circle one)
Very
Dissatisfied
Very
1
$\begin{array}{lllll}2 & 3 & 4 & 5\end{array}$
$\begin{array}{lllll}2 & 3 & 4 & 5\end{array}$
$\begin{array}{lllll}2 & 3 & 4 & 5\end{array}$
Satisfied

15. Do you participate in outdoor adventure activities (for example rock climbing, river rafting, off-road vehicles, scuba diving, etc.) with family members?

\begin{tabular}{|c|c|c|c|}
\hline \multicolumn{4}{|c|}{$\mathrm{NO}$} \\
\hline If YES how often? & \multicolumn{3}{|c|}{ For about how long per time? (check only one) } \\
\hline At least daily & $<1$ hour & $1-2 \mathrm{hrs}$ & 2-3 hours \\
\hline At least weekly & 3-4 hours & 4-5 hours & 5-6hours \\
\hline At least monthly & 6-7 hours & 7-8 hours & 8-9 hours \\
\hline At least annually & 9-10 hours & $>10$ hours & \\
\hline & 1 day & 8 days & 15 days \\
\hline & 2 days & 9 days & 16 days \\
\hline & 3 days & 10 days & 17 days \\
\hline & 4 days & 11 days & 18 days \\
\hline & 5 days & 12 days & 19 days \\
\hline & 6 days & 13 days & 20 days \\
\hline & One week & Two weeks & $\begin{array}{r}3 \text { or more } \\
\text { weeks }\end{array}$ \\
\hline
\end{tabular}

How satisfied are you with your participation with family members in these activities? (please circle one)

Very

Dissatisfied

1
Very

Satisfied

4

5 
16. Do you participate in tourism activities (for example family vacations, traveling, visiting historic sites, visiting state/national parks, etc.) with family members?

YES _ _ NO

\begin{tabular}{|l|l|}
\hline \multicolumn{2}{|c|}{ If YES how often? } \\
\hline At least daily & \\
\hline At least weekly & \\
\hline At least monthly & \\
\hline At least annually & \\
\hline
\end{tabular}

\begin{tabular}{|r|r|r|r|r|}
\hline \multicolumn{5}{|c|}{ For about how long per time? (check only one) } \\
\hline$<1$ hour & $1-2$ hrs & 2 -3 hours & \\
\hline 3-4 hours & $4-5$ hours & 5 -6hours & \\
\hline 6-7 hours & $7-8$ hours & & 8 -9 hours & \\
\hline 9-10 hours & $>10$ hours & & & \\
\hline 1 day & 8 days & 15 days & \\
\hline 2 days & 9 days & 16 days & \\
\hline 3 days & 10 days & 17 days & \\
\hline 4 days & 11 days & 18 days & \\
\hline 5 days & 12 days & 19 days & \\
\hline 6 days & 13 days & 20 days & \\
\hline One week & Two weeks & 3 or more \\
& & & weeks & \\
\hline
\end{tabular}

How satisfied are you with your participation with family members in these activities? (please circle one)

\section{Very}

Dissatisfied

1
2
Very

Satisfied 
Below are seven statements with which you may agree or disagree. Using the 1-7 scale below, indicate your agreement with each item by circling the appropriate number on the line following that item. Please be open and honest in responding.

$\begin{array}{ccccccc}1 & 2 & 3 & 4 & 5 & 6 & 7 \\ \text { strongly } & \text { disagree } & \text { slightly } & \text { neither agree } & \text { slightly } & \text { agree } & \text { strongly } \\ \text { disagree } & & \text { disagree } & \text { nor disagree } & \text { agree } & & \text { agree }\end{array}$

1. In most ways my family life is close to ideal $\quad \begin{array}{llllllll}1 & 2 & 3 & 4 & 5 & 6 & 7\end{array}$

2. The conditions of my family life are excellent. $\begin{array}{lllllllll}1 & 2 & 3 & 4 & 5 & 6 & 7\end{array}$

$\begin{array}{lllllllll}\text { 3. I am satisfied with my family life. } & 1 & 2 & 3 & 4 & 5 & 6 & 7\end{array}$

4. So far I have gotten the important things I want $\quad \begin{array}{lllllllll}1 & 2 & 3 & 4 & 5 & 6 & 7\end{array}$

in my family life

5. If I could live my family life over, I would $\quad \begin{array}{lllllllll}1 & 2 & 3 & 4 & 5 & 6 & 7\end{array}$

change almost nothing

6. Family leisure activities are an important part $\quad \begin{array}{lllllllll}1 & 2 & 3 & 4 & 5 & 6 & 7\end{array}$

of our family life.

$\begin{array}{llllllllll}\text { 7. Family leisure adds to the quality of my family } & 1 & 2 & 3 & 4 & 5 & 6 & 7\end{array}$ life.

(Zabriskie, 2000) 
Appendix A-1c

Family Adaptability and Cohesion Scale II 


\section{Family Adaptability and Cohesion Scales}

\section{(FACES II)}

Please answer the following questions in reference to your family currently. Please be as open and honest as possible. All responses are strictly confidential.

Use the following scale:

1

Almost never Once in awhile
3

Sometimes
4 Frequently
5

Almost always

\section{Describe your family:}

1. Family members are supportive of each other during difficult times.

2. In our family, it is easy for everyone to express his/her opinion.

3. It is easier to discuss problems with people outside the family than with other family members.

4. Each family member has input regarding major family decisions.

5. Our family gathers together in the same room.

6. Children have a say in their discipline.

7. Our family does things together.

8. Family members discuss problems and feel good about the solutions.

9. In our family, everyone goes his/her own way.

10. We shift household responsibilities from person to person.

11. Family members know each other's close friends.

12. It is hard to know what the rules are in our family.

13. Family members consult other family members on personal decisions.

14. Family members say what they want.

15. We have difficulty thinking of things to do as a family.

16. In solving problems, the children's suggestions are followed.

17. Family members feel very close to each other.

18. Discipline is fair in our family.

19. Family members feel closer to people outside the family than to other family members.

20. Our family tries new ways of dealing with problems.

21. Family members go along with what the family decides to do.

22. In our family, everyone shares responsibilities.

23. Family members like to spend their free time with each other.

24. It is difficult to get a rule changed in our family.

25. Family members avoid each other at home.

26. When problems arise, we compromise.

27. We approve of each other's friends.

28. Family members are afraid to say what is on their minds.

29. Family members pair up rather than do things as a total family.

30. Family members share interests and hobbies with each other.

(Olson, 1986) 
Appendix A-1d

Dyches Adapted Support/Skills Scale 


\section{Child (with Special Needs) Description}

\section{Adaptive Skills/Levels of Supports}

*If you have more than one child with a developmental disability, please refer to the same child you chose for the previous questions to answer the following questions.*

Please rate your child's need for support in the following areas, based upon the following criteria:

1 = Intermittent: $\quad$ Supports are provided on an "as needed" basis, temporary,

2 = Limited: $\quad$ Supports are provided on a regular basis for a short period of time, in several settings.

3 = Extensive: $\quad$ Supports are needed regularly (e.g., daily) in several settings and may extend over long periods of time.

4 = Pervasive: $\quad$ Supports are constant and intense in all settings. They may be life-sustaining.

(1) Communication (understand others and express self)

(2) Self-Care (toileting, eating, dressing, hygiene, grooming)

(3) Home Living (clothing care, housekeeping, cooking, home safety)

(4) Social Skills (interact with others, cope with demands, obey rules, peer acceptance)

(5) Community Use (travel, shop, use public facilities, church)

(6) Self-Direction (make choices, follow a schedule, seek assistance, resolve problems)

(7) Health \& Safety (eating, illness identification, basic first aid, physical fitness) studies)

(8) Academics (writing, reading, math, science, health, geography, social

(9) Leisure (play, recreational activities, personal choices)

(10) Work (part or full-time job, related work skills, money management)

(11) Mobility (ability to get from one place to another)

(Dyches, 2000) 
Appendix A-1e

Demographic Questions 
Demographic Questions (Youth)

What is your gender?

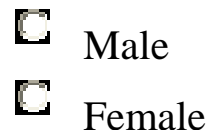

What is your age?

What is your ethnicity?

C Asian

C Black, non-hispanic

C Hispanic

C Native American

C Pacific Islander

C White, non-hispanic 


\section{Demographic Questions (Parent)}

The following section asks some general questions about you and your family.

What is your age?

What is your gender?

C Male

C Female

Please indicate the total number of immediate family members (parent[s] and child[ren])

Family Composition — Please enter the following information about your family*:

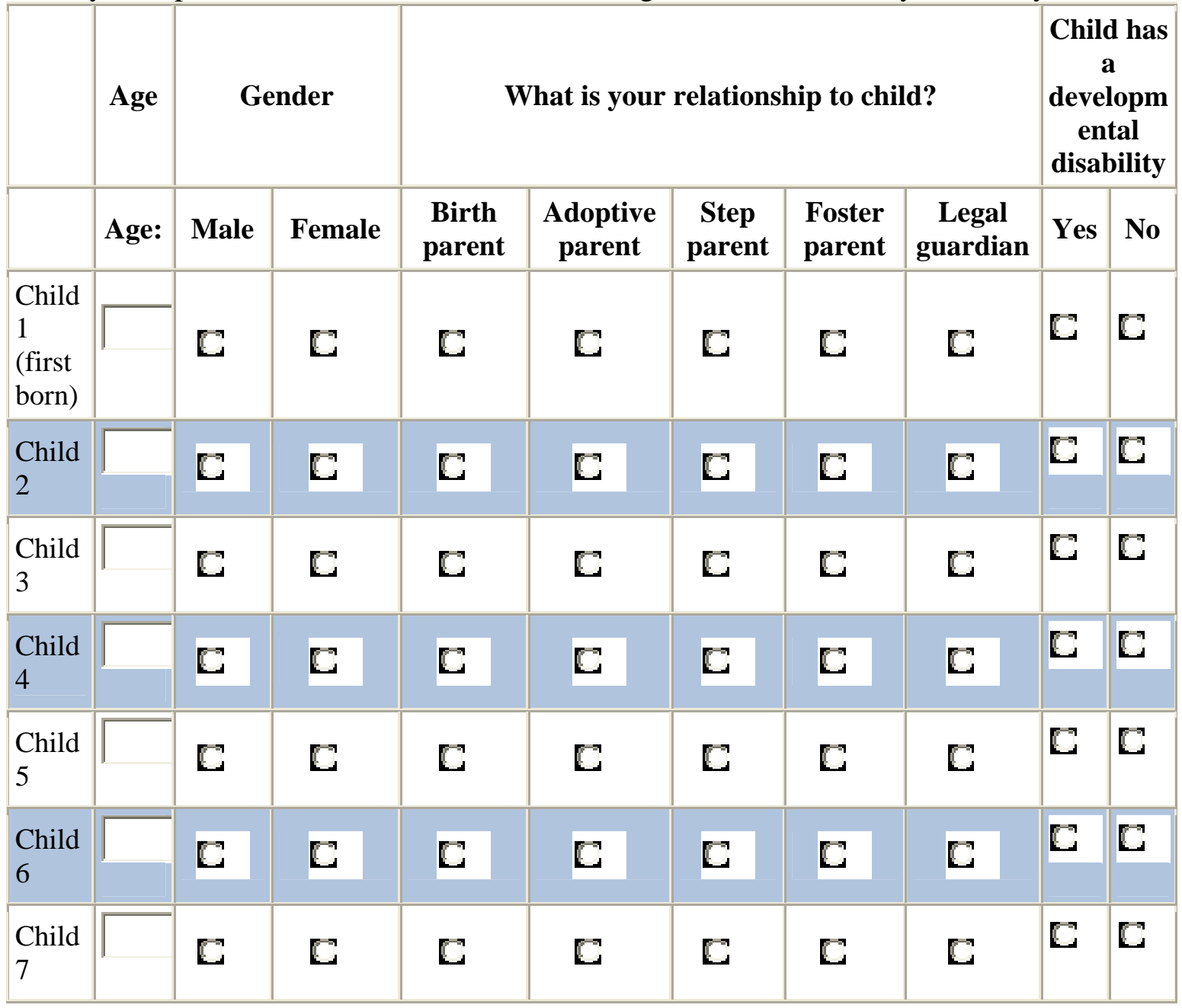


*Only fill out what applies to your family. Not all answer fields required.

Have you ever been divorced?

$\begin{array}{ll}\boldsymbol{C} & \text { Yes } \\ \text { C } & \text { No }\end{array}$

Ethnic Background

C Asian

C Pacific Islander

C Black not Hispanic

C Hispanic

C Native American

C White, not Hispanic

C Other

If other, please specify:

Please indicate the estimated annual income for your family. (Click here to choose)

State currently living in (if in Canada, please select Canada): (Click here to choose)

Population of your place of residency:

C Urban/Suburban $(>50,000)$

C Rural $(<50,000)$

Marital status:

C Single - Never Married

C Separated

C Divorced

C Widowed 
C Unmarried - Living with Partner

C Married

If you have more than one child with a developmental disability, please choose one to answer the following questions about:

Age of child with a developmental disability (in years):

(Click here to choose)

Length of time the child with the developmental disability has been in your family.

C 0-2 years

C 3-5 years

C 6-8 years

C $9+$ years

What is the primary diagnosis of the child with the developmental disability?

C Aspergers

Attention deficit hyperactivity disorder

C Autism

C Brain abnormalities

C Cerebral palsy

C Down syndrome

C Fragile X syndrome

C Mental retardation

C Rubenstein-tabyi syndrome

C Traumatic brain injury

C Other

If Other, please specify: 
Please list any additional diagnoses:

What is the IQ level of the child with the developmental disability?

C Untestable

C $<25$

C $<40$

C $<55$

C $<70$

C $<85$

C $<100$

C $<115$

C $<130$

C $<145$

C Unknown

Do you have another child with a developmental disability?

C Yes

$\mathbf{C}_{\text {No }}$

What is the primary diagnosis of the second child with the developmental disability?

C Aspergers

C Attention deficit hyperactivity disorder

C Autism

C Brain abnormalities

C Cerebral palsy

C Down syndrome

C Fragile X syndrome

C Mental retardation

C Rubenstein-tabyi syndrome 
C Traumatic brain injury

C Other

Do you have another child with a developmental disability?

C Yes

C No 